\title{
Accurate Assessment of the Oxygen Reduction Electrocatalytic Activity of Mn/Polypyrrole Nanocomposites Based on Rotating Disk Electrode Measurements, Complemented with Multitechnique Structural Characterizations
}

\author{
Patrizia Bocchetta, ${ }^{1}$ Carolina Ramírez Sánchez, ${ }^{2}$ \\ Antonietta Taurino, ${ }^{3}$ and Benedetto Bozzini ${ }^{1}$ \\ ${ }^{1}$ Dipartimento di Ingegneria dell'Innovazione, Università del Salento, Via Monteroni, 73100 Lecce, Italy \\ ${ }^{2}$ Centro de Investigación, Innovación y Desarrollo de Materiales-CIDEMAT, Universidad de Antioquia UdeA, \\ Calle 70 No. 52-21, Medellín, Colombia \\ ${ }^{3}$ Institute for Microelectronics and Microsystems, IMM-CNR, Via Monteroni, 73100 Lecce, Italy
}

Correspondence should be addressed to Patrizia Bocchetta; patrizia.bocchetta@unisalento.it

Received 21 August 2016; Revised 18 October 2016; Accepted 19 October 2016

Academic Editor: Chih-Ching Huang

Copyright @ 2016 Patrizia Bocchetta et al. This is an open access article distributed under the Creative Commons Attribution License, which permits unrestricted use, distribution, and reproduction in any medium, provided the original work is properly cited.

\begin{abstract}
This paper reports on the quantitative assessment of the oxygen reduction reaction (ORR) electrocatalytic activity of electrodeposited Mn/polypyrrole (PPy) nanocomposites for alkaline aqueous solutions, based on the Rotating Disk Electrode (RDE) method and accompanied by structural characterizations relevant to the establishment of structure-function relationships. The characterization of Mn/PPy films is addressed to the following: (i) morphology, as assessed by Field-Emission Scanning Electron Microscopy (FE-SEM) and Atomic Force Microscope (AFM); (ii) local electrical conductivity, as measured by Scanning Probe Microscopy (SPM); and (iii) molecular structure, accessed by Raman Spectroscopy; these data provide the background against which the electrocatalytic activity can be rationalised. For comparison, the properties of $\mathrm{Mn} / \mathrm{PPy}$ are gauged against those of graphite, PPy, and polycrystalline-Pt (poly-Pt). Due to the literature lack of accepted protocols for precise catalytic activity measurement at poly-Pt electrode in alkaline solution using the RDE methodology, we have also worked on the obtainment of an intralaboratory benchmark by evidencing some of the time-consuming parameters which drastically affect the reliability and repeatability of the measurement.
\end{abstract}

\section{Introduction}

Notwithstanding the astonishing discrepancies among the ORR activities reported from different laboratories and typically attributed to experimental protocols, electrode conditioning, and current-potential curves corrections [1], the RDE technique-together with the RDDE one-seems to be the method most used by the electrochemists to characterize ORR electrocatalysts. The reasons are simplicity and speed of the measurements as well as commercial availability and low cost of all the required facilities. For this specific electroanalytic application, poly-Pt can be considered as a standard electrode that, notwithstanding the intrinsically poorly defined nature of a polycrystalline surface, exhibits a very robust and reproducible electrochemical response. Moreover, since standardized disks of poly-Pt are commercially available at convenient costs, their use as benchmark electrodes for the ORR electrocatalytic studies seems appropriate. At present, ORR at Pt RDE electrodes of different forms (wires, gauzes, foils, and disks of different areas) has been widely investigated in acid solution [1-3], due to their relevance in polymer electrolyte fuel cells [4]. On the contrary marginal attention has been paid to pure Pt in alkaline solutions (single crystal Pt [5, 6], poly-Pt particles [7], poly-Pt wire [8], poly-Pt thin film [9-11], and poly-Pt rod [6, 12-14]) despite the fact that ORR plays a key role in the chlor-alkali technology and in 
metal-air batteries $[15,16]$. Due to the absence of an interlaboratory benchmark material in alkaline solution and the discrepancies in the few data available at the moment $[6,12-$ $14]$, we have realized an intralaboratory poly-Pt benchmark against which the data gathered with novel ones can be safely gauged.

Limited interest for Pt as ORR electrocatalyst in alkaline solution is probably justified by high costs, less aggressive chemical conditions, and lower catalytic activity and efficiency due to $\mathrm{HO}_{2}{ }^{-}$generation [17]. For these reasons, research in alkaline ORR has been centred on catalysts featuring nonnoble metals [18] such as palladium [19], ruthenium [20], iron [21, 22], nickel and cobalt mainly in the form of spinels [23-26], perovskites [27, 28], and manganese oxides $[14,29-36]$. In particular, $\mathrm{MnO}_{x}$ are the most studied systems for applications in metal/air batteries [16, 37, 38] owing to their low cost, adequate electrochemical stability, and good catalytic activity towards the decomposition of $\mathrm{HO}_{2}{ }^{-}$species produced by the ORR $2 e^{-}$pathway in alkaline solution $[30,31]$. One of the main limits of $\mathrm{MnO}_{x}$-based ORR electrocatalysts is their poor electrical conductivity: to overcome this problem commercial air cathodes have to be fabricated by combining oxides with conducting materials, mainly carbon nanoparticles [39]. Among other approaches favouring electronic contact to $\mathrm{MnO}_{x}$, the dispersion of metal oxide particles in a polypyrrole ( $\mathrm{PPy}$ ) matrix is also appealing for a series of physicochemical reasons, detailed in [4043]. Among Mn/PPy fabrication routes, electrodeposition offers the possibility of forming directly Mn particles into the polymer layer $[44,45]$ or of entrapping metal complexes that yield metal particles during a subsequent reduction step [46]. The first studies that have demonstrated the possibility of increasing the mixed oxide conductivity by using PPy [40] also showed that the deposition of alternating layers of $\mathrm{PPy}$ and $\mathrm{MnCu}$ or $\mathrm{NiCu}$ oxide spinel particles protects the catalytic sites against dissolution during ORR operation. Recently, an alternative facile synthesis of composite metal oxide/PPy electrocatalysts has been proposed, based on onepot electrodeposition onto conductive substrates [47-52].

In this paper we have focused on the quantitative and reproducible assessment of the ORR activity of electrodeposited Mn/PPy nanocomposites in aqueous alkaline ambient, by using poly-Pt electrodes as intralaboratory benchmark material. The electrocatalytic results are complemented by a morphological and structural characterization of our materials by FE-SEM, AFM, conductivity-probe SPM, and Raman Spectroscopy.

\section{Materials and Methods}

2.1. Materials and Electrodes. The Mn/PPy electrodeposition bath contains the following: $0.1 \mathrm{M}$ pyrrole, $25 \mathrm{mM}$ $\mathrm{MnCl}_{2}, 0.1 \mathrm{M}$ tetrabutyl-ammonium-perchlorate (TBAP), and $1 \% \mathrm{v} / \mathrm{v} \mathrm{H}_{2} \mathrm{O}$ dissolved in acetonitrile. Acetonitrile, $\mathrm{MnCl}_{2} \cdot 4 \mathrm{H}_{2} \mathrm{O}$, pyrrole, and TBAP were supplied by Aldrich. Before each PPy electrodeposition experiment, the pyrrole monomer was distilled under rotary pump vacuum several times (typically three) until it becomes colourless. All the solutions were prepared with ultrapure water from a Milli-Q system (Millipore, Vimodrone (MI), Italy), exhibiting a resistivity of $18.2 \mathrm{M} \Omega \mathrm{cm}$. Polycrystalline- $\mathrm{Pt}$ (Poly-Pt) rod was mechanically polished with different grades of grit paper, down to $0.05 \mu \mathrm{m}$ diamond paste, and then accurately rinsed with double-distilled water. To guarantee an initial reproducible surface, the working electrode was held for $5 \mathrm{~s}$ at $1.40 \mathrm{~V} / \mathrm{RHE}$, a potential which a full coverage of platinum surface by $\mathrm{O}$-containing species is attained to, followed by an electroreduction step to $1.13 \mathrm{~V} / \mathrm{RHE}$ for $1 \mathrm{~min}$ [9]. The surface of the graphite $(G)$ was treated according to the following procedure: (i) polishing to mirror finish; (ii) $10 \mathrm{~min}$ ultrasonication (US) in ultrapure $\mathrm{H}_{2} \mathrm{O}$; (iii) repolishing to mirror finish; (iv) $10 \mathrm{~min}$ US in acetone US; and (v) 10 min US in ultrapure $\mathrm{H}_{2} \mathrm{O}$. Electrochemical synthesis was performed using a three-electrode cell with a graphite disk $(\Phi=1.35 \mathrm{~mm})$, as working electrode (WE), a Pt wire as counter electrode (CE), and an aqueous silver/silver chloride ( $\mathrm{Ag} / \mathrm{AgCl} / 3 \mathrm{M}: 0.209 \mathrm{~V} / \mathrm{NHE})$ as reference electrode (RE). All potentials are reported versus the reversible hydrogen electrode (RHE) scale.

2.2. Electrochemical Measurements and Methods. The electrochemical measurements were carried out at room temperature using a ParStat 2273 potentiostat. The Mn/PPy catalysts were synthesized in deaerated electrodeposition baths. Electrodeposition was carried out with the pulsed potential procedure described in previous works [47, 48, 50, 51] optimized in view of growing a composite consisting of two constituents that are formed anodically (PPy and $\mathrm{Mn}(\mathrm{III}, \mathrm{IV})$ compounds) and cathodically $(\mathrm{Mn}(0)$ and/or precipitated $\mathrm{Mn}$ (II) containing species). The initial step $(0.971 \mathrm{~V} / \mathrm{RHE})$ does not lead to faradaic reactions, but it is required to relax the compositional double layer. After this relaxation step, a layer of PPy is electrodeposited during the first anodic pulse $(2.17 \mathrm{~V})$. During the subsequent cathodic pulse $(0.829 \mathrm{~V})$, reduced $\mathrm{Mn}(0)$ or precipitated $\mathrm{Mn}$ (II) species can be incorporated into PPy. In the final anodic step of each cycle $(2.17 \mathrm{~V})$, another layer of-possibly Mndoped-PPy is deposited. After electrochemical synthesis, the films were rinsed with pure acetone and dried at room temperature.

2.3. Morphological Characterization. The morphology of $\mathrm{Mn} / \mathrm{PPy}$ catalyst electrodeposited onto graphite discs was investigated by Field-Emission Scanning Electron Microscopy (FE-SEM) using an NVISION 40 Zeiss, equipped with a high resolution Gemini Field-Emission Gun and with an Oxford INCA 350 Xact Energy Dispersive X-Ray (EDX) Spectrometer. Details about the morphological features at the nanoscale and quantitative analysis of roughness and surface area were obtained with a Nanoscope III Multimode Atomic Force Microscope (AFM) (Bruker) in air using the ScanAsyst mode and the ScanAsyst probe (Bruker). On each sample 5 different square areas of sizes 1,5 , and $20 \mu \mathrm{m}$ were scanned at rates of 0.7 and $1.5 \mathrm{~Hz}$. The electrical conductivity of the sample was mapped by the PeakForce TUNA Module (Bruker) using a Pt/Ir probe (PF-TUNA $0.4 \mathrm{~N} / \mathrm{m}$, Bruker). AFM image analysis was carried out with the Nanoscope Analysis 1.5 program (Bruker). 
2.4. Raman Spectroscopy. Raman spectra were recorded using a LabRam microprobe confocal system. A 10x longworking distance objective was used and the excitation line at $632.8 \mathrm{~nm}$ was provided by a $12 \mathrm{~mW} \mathrm{He-Ne} \mathrm{laser.} \mathrm{The} \mathrm{slit} \mathrm{and}$ pinhole were set at 200 and $400 \mu \mathrm{m}$, respectively, corresponding to a scattering volume of $\sim 3 \mathrm{pL}$; Raman spectra were acquired with a $600 \mathrm{grid} / \mathrm{mm}$ spectrometer. The recorded Raman intensities are directly proportional to the discharge current of the CCD detector.

2.5. ORR Electrocatalytic Measurements. Oxygen reduction reaction (ORR) linear sweep voltammetries (LSV) on Mn$\mathrm{PPy} / \mathrm{C}$ electrodes were recorded to evaluate the catalytic activity in an $\mathrm{O}_{2}$-saturated (SIAD 6.0) $0.1 \mathrm{M} \mathrm{KOH}$ electrolyte at quasi-steady-state $\left(5 \mathrm{mV} \mathrm{s}^{-1}\right)$ at different Rotating Disk Electrode (RDE) rotation speeds. Graphite disks with $\mathrm{Mn} / \mathrm{PPy}$ electrodeposit were mounted in a Rotating Disk Electrode System (ParStat Model 2273, Photo Analytical S.R.L., Settala (MI), Italy). The same electrochemical experiments were duplicated with solutions that had been deoxygenated by $\mathrm{N}_{2}$ saturation. The current densities are referred to the electrode geometric area $\left(1.326 \mathrm{~cm}^{2}\right) . \mathrm{O}_{2}$ was bubbled for $20 \mathrm{~min}$ into the solution before the measurements and an $\mathrm{O}_{2}$ blanket was kept above the electrolyte during the measurement. In order to minimize disturbing effects of bubbles during the experiments, the electrolyte saturation has been performed at open circuit for $20 \mathrm{~min}$ and the pipette allowing gas into the solution was raised during the $\mathrm{RDE}$ measurement leaving a gas blanket over the solution. Special care was taken to avoid contingent ambient air suction into the analysis compartment caused by the electrode rotation. The ORR Levich slopes were estimated from current-voltage curves which the $\mathrm{N}_{2}$-background had been subtracted from.

\section{Results and Discussion}

\subsection{The RDE Measurement}

3.1.1. Theoretical Aspects. As it is well known from the literature [53], $\mathrm{RDE}$ is an electrochemical technique based on controlled electrolyte convection, leading to a well characterized fluid velocity distribution on the working electrode, provided that appropriate boundary conditions are implemented in cell and electrode mounting as well as in the real shaft rotation process. In the RDE method a discoidal electrode (e.g., glassy carbon or platinum), embedded in a rod of an insulating material (e.g., glass or Teflon), connected to a motor, rotates at a certain frequency $f=\omega / 2 \pi$, where $\omega$ is the angular velocity (Figures $1(\mathrm{a})$ and $1(\mathrm{~b})$ ). The $\mathrm{RDE}$ technique operates on the principle of controllable stationary limiting currents, where the diffusion layer at the electrode maintains its thickness constant over time. To this end, the effective electrode surface and the scan rate are kept to values in correspondence of which double-layer charging produces a vanishing current. Under these hypotheses, the mass transfer process can be described with simple equations that allow correlating the experimental parameters to the mass transfer of reactants to the electrode surface. When an electrode is rotated, mass transfer of reactants and products is governed by convective-diffusion mechanisms. At the RDE the hydrodynamic flow pattern results from centrifugal forces that move the liquid horizontally out and away from the centre of the disk (Figure 1(c)) while fresh solution continually replaces it by a flow normal to the electrode surface (Figure 1(a)). Of course, for these condition to hold true, a set of conditions have to be met, the details of which are provided, for example, in [53].

The convective-diffusion equations imply the existence of a diffusion layer of quiescent electrolyte on the electrode surface, within which mass transfer takes place only by diffusion. Outside this layer of thickness $\delta$, the convection maintains the concentrations of all species uniform and equal to the bulk values (Figure 1(d)). According to this model, by introducing the adjustable parameter $\delta$, the convection problem is formally treated as a diffusional one [54]. $\mathrm{O}_{2}$ diffusion to the catalyst surface may thus be modelled as illustrated in Figure 1(d): $\mathrm{O}_{2}$ diffuses through the boundary layer $(\delta)$ in the electrolyte solution yielding a controlled $\mathrm{O}_{2}$ flux/limiting current. In the relevant geometry the steadystate convective-diffusion equation with mass-transport controlled source term can be solved analytically, yielding the Koutecky-Levich (K-L) equations [54]:

$$
\begin{aligned}
\frac{1}{j} & =\frac{1}{j_{L}}+\frac{1}{j_{K}}=\frac{1}{B \cdot \sqrt{\varrho}}+\frac{1}{j_{K}}, \\
B & =0.62 \cdot n \cdot F \cdot C_{o} \cdot\left(D_{o}\right)^{2 / 3} \cdot v^{-1 / 6},
\end{aligned}
$$

where $j_{K}$ is the kinetic current density; $j_{L}$ the diffusionlimiting current density; $j$ the measured current density; $B$ the reciprocal of the slope; $\emptyset$ the angular velocity of the disk; $F$ the Faraday constant; $C_{0}$ the saturation concentration of $\mathrm{O}_{2}$ in $0.1 \mathrm{M} \mathrm{KOH}$ at room temperature $\left(1.210^{-6} \mathrm{~mol} \mathrm{~cm}^{-3}\right) ; D_{0}$ the diffusion coefficient of oxygen in water $\left(1.7310^{-5} \mathrm{~cm}^{2} \mathrm{~s}^{-1}\right)$; $v$ the kinematic viscosity of the solution at room temperature $\left(0.01 \mathrm{~cm}^{2} \mathrm{~s}^{-1}\right)$ [55]; and $n$ the electron transfer number.

3.1.2. Methodological Aspects. The literature survey on ORR at poly-Pt electrode in alkaline solution using the RDE methodology is limited and not consistent [6, 12-14]; therefore a definite comparison between the new developed $\mathrm{Mn}$-PPy material and the state-of-the-art electrocatalysts is not allowed. As a consequence, we have worked to obtain an intralaboratory benchmark (poly-Pt rod) not aiming at proposing a standard $\mathrm{RDE}$ curve usable as reference for general activity of poly-Pt (to do that a dedicated work of analysis on the different parameters affecting the ORR activity is necessary, together with interlaboratory testing; this kind of work is actually a challenge especially in alkaline solution) but only at acquiring an internal reference on the basis of which our novel data can be safely evaluated. In Section 3.1.2's (1) and (2) the effects of (i) the distance (s) between the catalytic surface and the electrolyte-free surface and (ii) the initial features of the catalyst surface on the reliability and reproducibility of the ORR measurements at RDE are discussed. Other experimental issues, such as glassware electrolyte impurity levels and uncompensated electrolyte resistance, slightly affect the results with errors less 


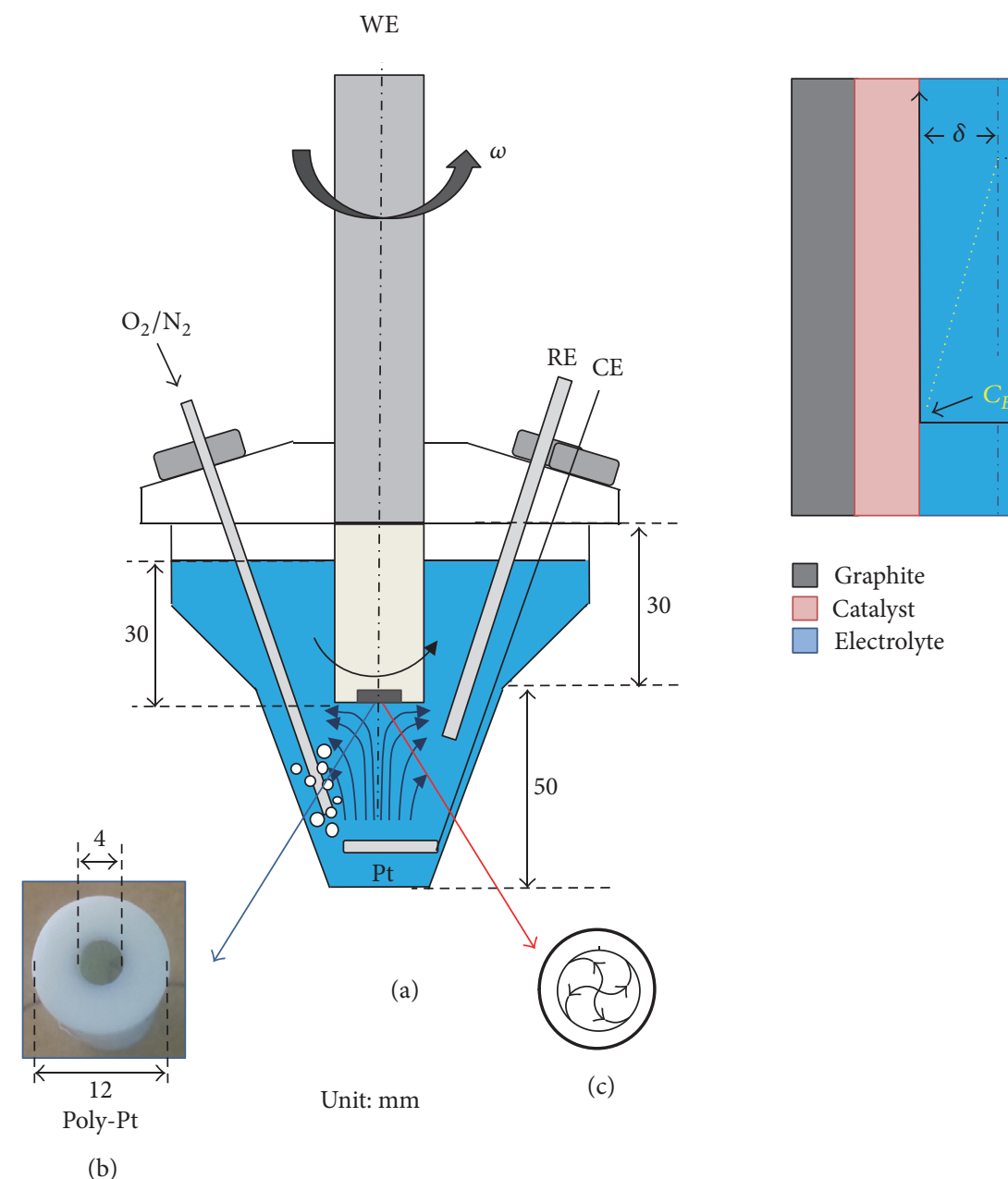

(d)

FIgURE 1: (a) Scheme of the electrochemical cell used for the ORR RDE experiment. (b) Macrograph of the poly-Pt electrode used for benchmark tests. (c) Representative flow lines on the electrode surface under rotation. WE, RE, and CE indicate working, reference, and counter electrodes, respectively. (d) Sketch of the catalyst-electrolyte interface depicting the linear $\mathrm{O}_{2}$ diffusion model that is incorporated in the K-L equation. The dotted line represents the $\mathrm{O}_{2}$ concentration distribution both in bulk electrolyte (black) and in the boundary layer (yellow). $\delta$ is the boundary layer thickness; $C_{\mathrm{BULK}}$ and $C_{E}$ are the $\mathrm{O}_{2}$ concentrations in the bulk and at the solution $\mid$ catalyst surface, respectively; $i_{L}$ is the $\mathrm{O}_{2}$ diffusion-limiting current.

than the $2 \%$, while dirty sliding electric contact of the rotator is responsible for a strong increase in the signal-to-noise ratio of the LSV curve (Figure 2(a), red curves).

(1) Electrochemical Cell Design. The electrochemical cell design significantly affects the hydrodynamic conditions of the electrolyte that must satisfy the above mentioned conditions (Section 3.1.1) to allow quantitative analysis according to the Levich equation. The cell and experimental conditions must be therefore designed so that the solution flow within the cell becomes laminar. In this work, we report a detailed cell design (see the scheme reported in Figure 1(a)) associated with the RDE voltammetric curves of ORR at poly-Pt and $\mathrm{Mn} / \mathrm{PPy}$ catalysts in $0.1 \mathrm{M} \mathrm{KOH}$. In our experiments, we have evidenced that the determination of the distance $(s)$ between the catalytic surface and the electrolyte-free surface (i.e., the electrolyte volume) radically improves the quality of $\mathrm{RDE}$ voltammetries due to achieved laminar flow at the reacting electrode surface. The optimal $s$ value was determined by experimental calibration and found to be $30 \mathrm{~mm}$, corresponding to a volume of the electrolyte of $80 \mathrm{~mL}$ (Figure 2(a)). In Figure 2(b) it can be observed that the effect of $s$ on the LSV curve is to modify (i) the Butler-Volmer behaviour under mixed kinetic control in the intermediate potential region and (ii) the curve repeatability. In Table 1 the scatter of current density values (standard deviation) obtained from repeated measurements at the same rotation rates is shown. Low $s$ values find out a low reproducibility because, due to the turbulence effects, the diffusion limited conditions are neither constant nor controllable during the potential scan. As a consequence, the limiting current determination is not possible without making fundamental errors.

(2) Initial Electrode Conditions. It is well known that the state and coverage of oxygen-containing species on platinum are a crucial factor in determining the electrocatalytic activity of 


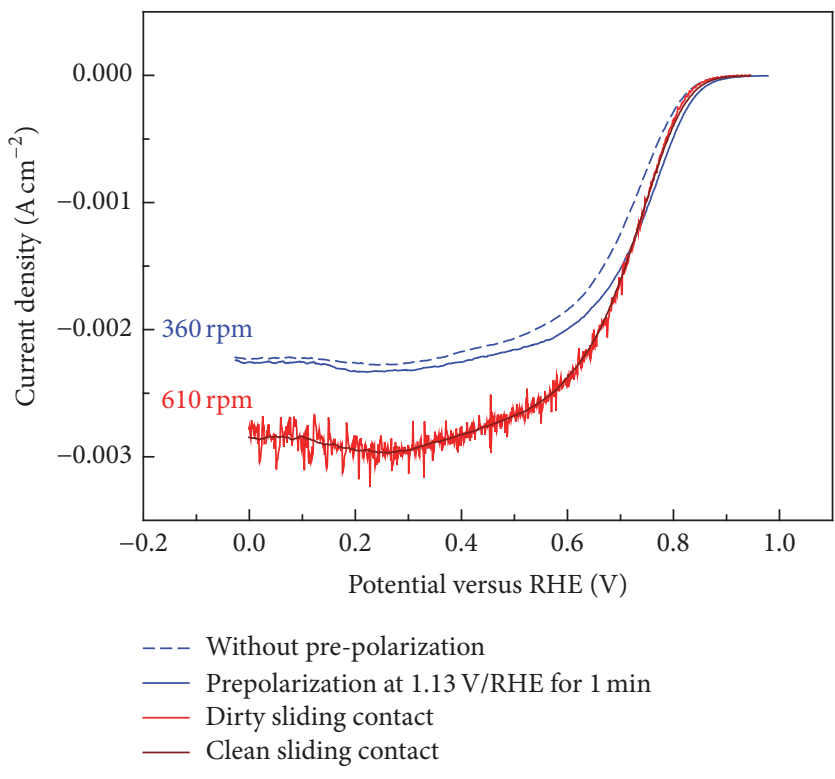

(a)

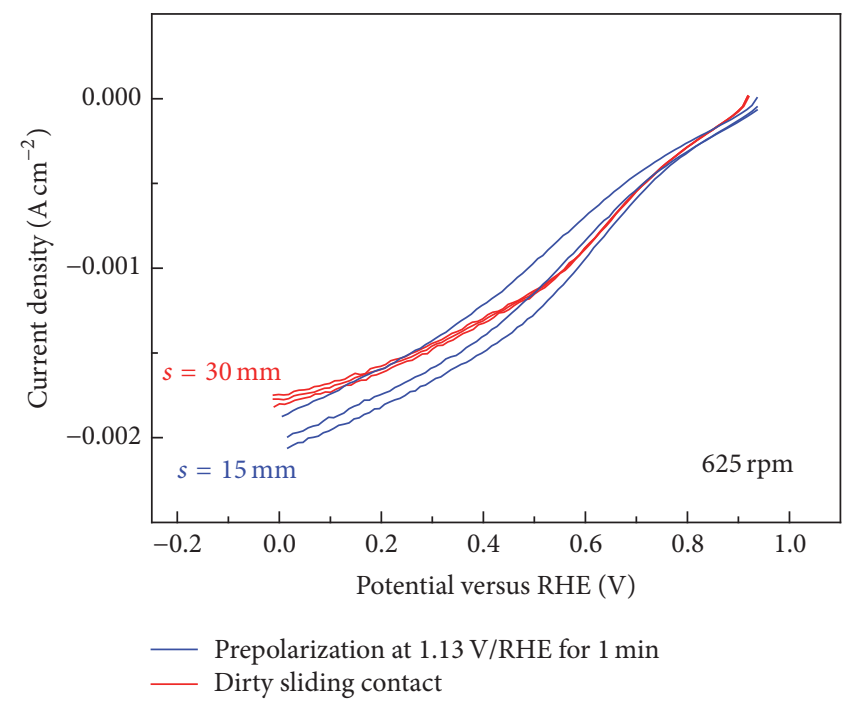

(b)

Figure 2: RDE voltammograms (scan rate: $5 \mathrm{mV} \mathrm{s}^{-1}$ ) in $\mathrm{O}_{2}$-saturated $0.1 \mathrm{M} \mathrm{KOH}$ evidencing the effect of the following: poly-Pt electrode before polarization (blue curves) and quality of the RDE sliding electric contacts (red curves) (a) and $s$ parameter of the cell design for Mn-PPy240/G (b). The $\mathrm{N}_{2}$ background has not been subtracted.

TABLE 1: Repeatability of RDE voltammograms (scan rate: $5 \mathrm{mV} \mathrm{s}^{-1}$ ) at $\mathrm{Mn} / \mathrm{PPy}$ catalyst in $\mathrm{O}_{2}$-saturated $0.1 \mathrm{M} \mathrm{KOH}$ evaluated at $625 \mathrm{rpm}$ and two $s$ values.

\begin{tabular}{lcccc}
\hline \multirow{2}{*}{ Applied potential, V/RHE } & & \multicolumn{2}{c}{ Current density, $\mathrm{mA} \mathrm{cm}^{-2}$} & \multicolumn{2}{c}{$s=30 \mathrm{~mm}$} \\
& Average value & Standard deviation & Average value & Standard deviation \\
\hline 0.8 & 0.29627 & 0.032422 & 0.2841 & 0.001082 \\
0.6 & 0,8248 & 0.125753 & 0.8803 & 0.005356 \\
0.4 & 1.3697 & 0.142935 & 1.3090 & 0.016000 \\
0.2 & 1.7189 & 0.114434 & 1.5957 & 0.019553 \\
\hline
\end{tabular}

platinum surfaces towards $\mathrm{O}_{2}$ reduction [9]. For this reason, the reproducibility of the initial surface of poly-Pt was assured by holding the electrode for $5 \mathrm{~s}$ at $1.40 \mathrm{~V} / \mathrm{RHE}$, a potential which a full coverage of platinum surface by $\mathrm{O}$-containing species is attained at, followed by an electroreduction step at $1.13 \mathrm{~V} / \mathrm{RHE}$ for $1 \mathrm{~min}$ [9]. The effect of this pretreatment reported in Figure 2(a) (blue curves) is to shift the onset and half-wave potential to more positive values. At low overpotentials the surface of untreated $\mathrm{Pt}$ is covered of oxygen intermediates strongly bonded with $\mathrm{Pt}$ that affect the activation energy of the ORR process, hindering the proton and electron transfer, while at high overpotentials their influence becomes negligible because the stability of the oxygen bond decreases and the ORR may proceed (the two curves overlap).

The surface initial conditions of Mn/PPy electrocatalyst are strictly related to the morphochemical goodness of the electrodeposit; this aspect is thoroughly discussed in Section 3.3 where the morphological and molecular structure of $\mathrm{Mn} / \mathrm{PPy}$ materials has been characterized by FE-SEM, AFM, conductivity-probe SPM, and Raman Spectroscopy in view of ORR performance evaluation.
3.2. The RDE Experiment at Poly-Pt Electrode in 0.1 $\mathrm{M} \mathrm{KOH}$. Poly-Pt rod has been used as intralaboratory benchmark material in alkaline solution for the study of ORR at MnPPy/G catalyst. The electrode (Figure 1(b)) has been pretreated using the protocol described in Section 3.1.2.(2). In Figure 3(a) we report ORR quasi-steady-state voltammograms of poly-Pt rod at a scan rate of $5 \mathrm{mV} \mathrm{s}^{-1}$ in $\mathrm{O}_{2}$-saturated $0.1 \mathrm{KOH}$ aqueous solutions at different $\mathrm{RDE}$ rotation speeds. Stable and reproducible voltammograms were obtained following the experimental details discussed in Section 3.1. At low overpotentials $(0-0.2 \mathrm{~V} / \mathrm{RHE})$ the curves are independent of the rotation speed, $\omega$, being the electrode kinetics governed by the charge transfer. At higher overpotentials instead, the increase of current density with potential becomes slower, as expected for an electrochemical reaction under mixed control, until the mass-transport kinetic contributions become significant and determine the appearance of a current plateau, which thus strongly depends on $\omega$. Sometimes a slight hump at $0.20 \mathrm{~V}$ is observed and presumably attributed to $\mathrm{H}$-adatom adsorption on platinum [13]. In agreement with the Levich equation (see (2)) the height of this plateau increases linearly with the square root 


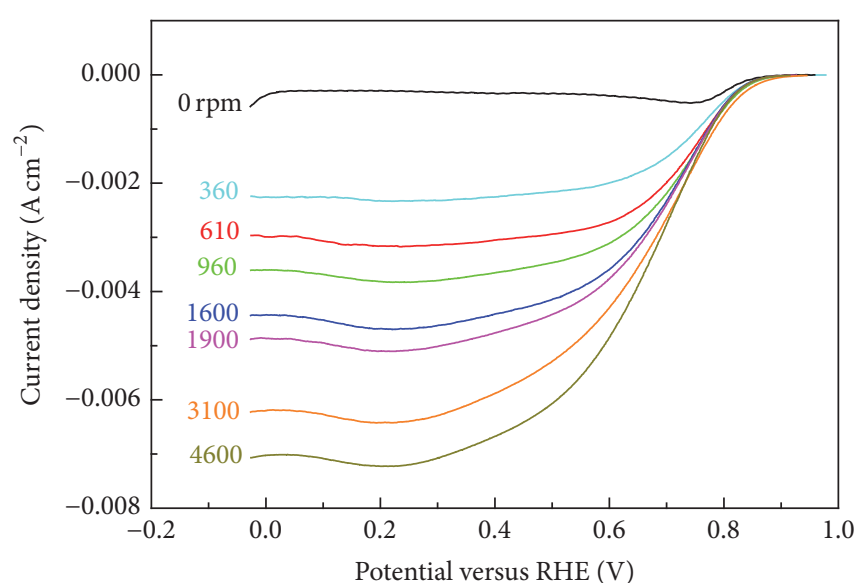

(a)

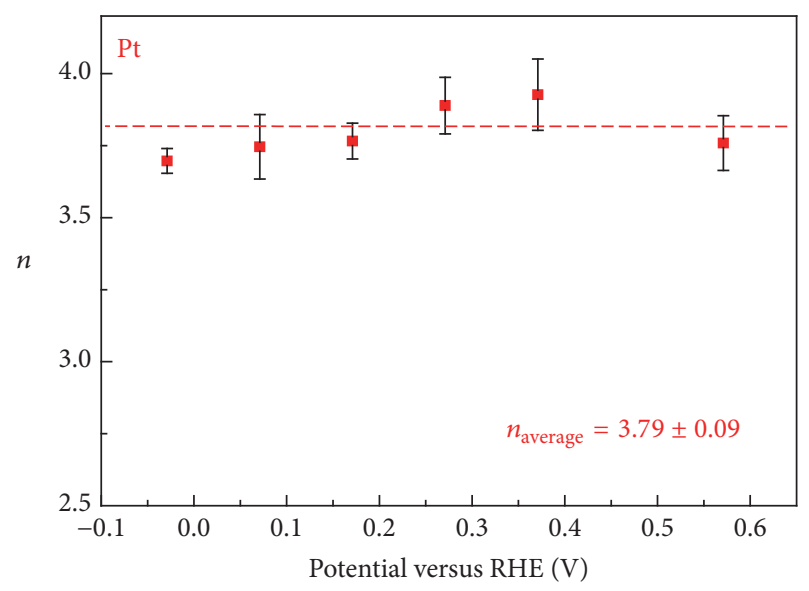

(c)

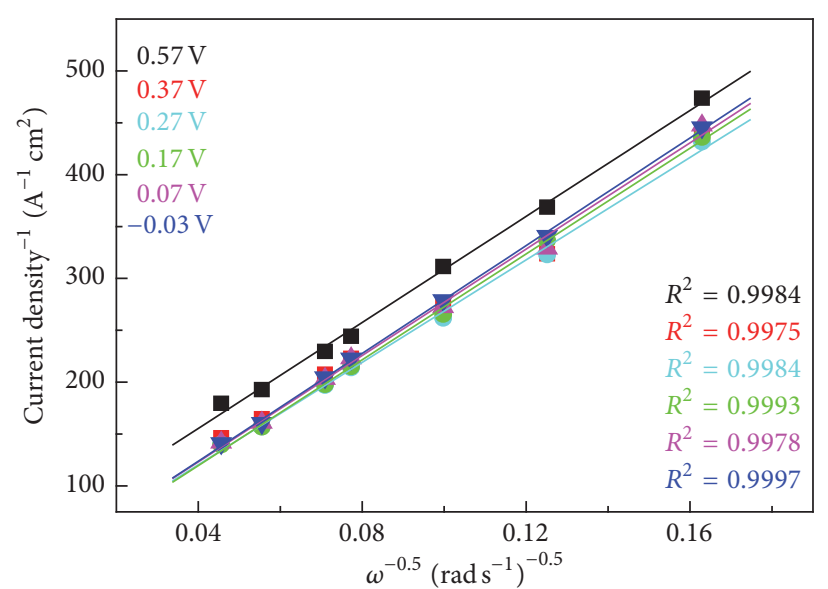

(b)

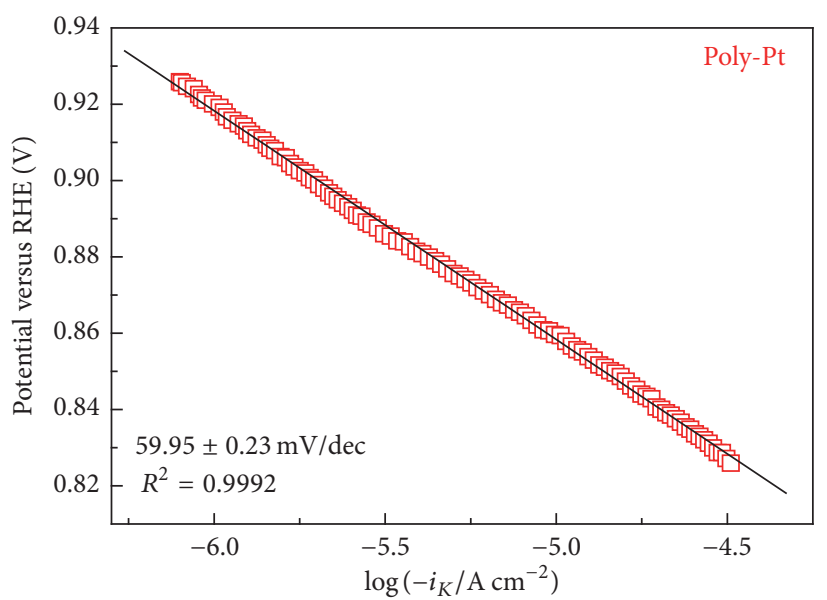

(d)

Figure 3: (a) RDE voltammograms (scan rate: $5 \mathrm{mV} \mathrm{s}^{-1}$ ) of poly-Pt electrode in $\mathrm{O}_{2}$-saturated $0.1 \mathrm{M} \mathrm{KOH}$ at different rotation speeds. The $\mathrm{N}_{2}$ background has been subtracted. (b) Koutecky-Levich plots derived from the curves of Panel (a) at a series of representative potentials. Symbols are experimental data; lines are the linear regressions. (c) Dependence of the electron transfer number $n$ on the electrode potential. (d) Tafel plot obtained from RDE voltammograms at $1600 \mathrm{rpm}$.

of $\omega$ as shown in Figure 3(b). The slopes of the linear fit lines to the experimental Levich plots were used to estimate $n$ according to (1) in a range of electrode potentials that are representative of practical electrocatalytic operation and reported in Figure 3(c). $n$ values, averaged in the potential range $-0.6 \div-0.1$, were found to be $3.79 \pm 0.09$, suggesting the prevalence of ORR four-electron mechanism typical of platinum.

The charge-transfer kinetic is shown in the Tafel plots of Figure 3(d), where ORR kinetic current $i_{k}$ is estimated according to $1 / i=1 / i_{L}+1 / i_{k}\left(i_{L}\right.$ : limiting current density). The Tafel slope is approximately $60 \mathrm{mV} \mathrm{dec}^{-1}$ in agreement with literature for Pt under alkaline conditions $(0.1-6.0 \mathrm{M}$ $\mathrm{KOH})$ in the low overpotential region $[10-13,56]$. This value, close to $-2.303 R T / \alpha F \approx 60 \mathrm{mV} / \mathrm{dec}$ (where $R$ is the molar gas constant, $T$ the absolute temperature, $\alpha$ the transfer coefficient, and $F$ the Faraday constant) at room temperature $[57,58]$, indicates that the transfer of the first electron catalysed by $\mathrm{Pt}$ is probably the rate-determining step.

\subsection{Characterization of $M n-P P y / G$ ORR Catalyst}

3.3.1. Morphological and Structural Characterization. The morphological, compositional, and chemical-state distribution of the as-deposited Mn/PPy material, using the same electrodeposition procedure employed for this investigation, has been studied in detail by soft X-ray fluorescence (XRF) mapping and microabsorption spectroscopy (micro-XAS) in a previous paper of ours [51]. This analysis disclosed a rather homogeneous $\mathrm{Mn}$ spatial distribution that is consistent in a rather wide range of current densities, while microXAS has revealed that the potentiostatic pulsed codeposition process-alternating anodic and cathodic polarization intervals-leads to a PPy deposit containing manganese (II, III, IV) oxyhydroxides and traces of $\mathrm{Mn}(0)$. A granular morphology was found in all the analyzed regions, with colocation of $\mathrm{Mn}, \mathrm{N}$, and $\mathrm{O}$, denoting the fact that $\mathrm{MnO}_{x}$ and polypyrrole act as nucleation centres for material electrodeposited in both the anodic and cathodic pulses. This is in agreement with the classical nucleation and growth 


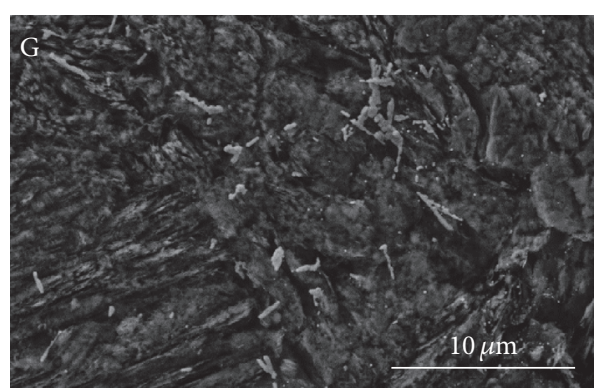

(a)

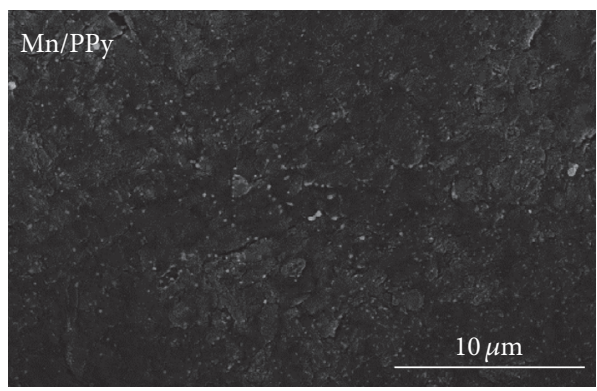

(c)



(b)

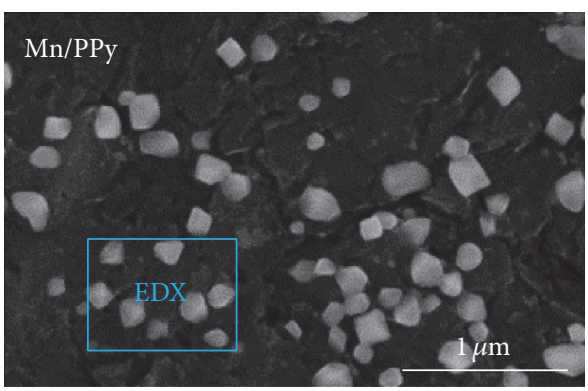

(d)



(e)

Figure 4: FE-SEM micrographs of (a) graphite, (b) PPy (PPy60/G), and (c, d) Mn/PPy electrodeposited on graphite (Mn-PPy240/G). (e) A typical EDX spectrum recorded in a representative area.

mechanism for electrodeposition by pulse-plating [59]. In this paper, we have assessed the morphological structure of the G substrate, of a pure PPy deposit after 60 electrodeposition cycles (PPy60/G), Mn/PPy after 60 cycles (MnPPy60/G), and Mn/PPy after 240 cycles (Mn-PPy240/G).

(1) FE-SEM and EDX Analyses. FE-SEM analysis has been used to assess the distribution of the deposit over the whole electrode area. Figure 4 reports the in-plane morphology at low magnification of the G, PPy/G, and MnPPy240/G samples. The $G$ substrate, treated as specified in Section 2.1, shows a highly structured morphology with a high surface area (Figure 4(a)); the electropolymerization of PPy leads to a film covering uniformly the G electrode (Figure 4(b)) while a uniform distribution of Mn-containing nanoparticles is disclosed after electrodeposition of $\mathrm{Mn} / \mathrm{PPy}$
(Figures 4(c) and 4(d)). The presence of Mn has been positively assessed by EDX analysis, a typical spectrum is shown in Figure 4(e).

(2) AFM and PF-TUNA Analysis. AFM analysis has been used to obtain quantitative morphological information on the surface: average grains size $\left(R_{\mathrm{Q}}\right)$, average roughness $\left(R_{A}\right)$, and the real surface area (data summarized in Table 1). PFTUNA analysis has been also performed to map the electrical conductivity.

Figure 5 reports AFM height images of $\mathrm{G}$ substrate and of the following electrodeposits: PPy60/G, Mn-PPy60/G, and Mn-PPy240/G. The AFM images of graphite substrate confirm the presence of a highly structured morphology and provide quantitative information on the roughness and surface area (Table 2). The electrodeposition of PPy for 60 


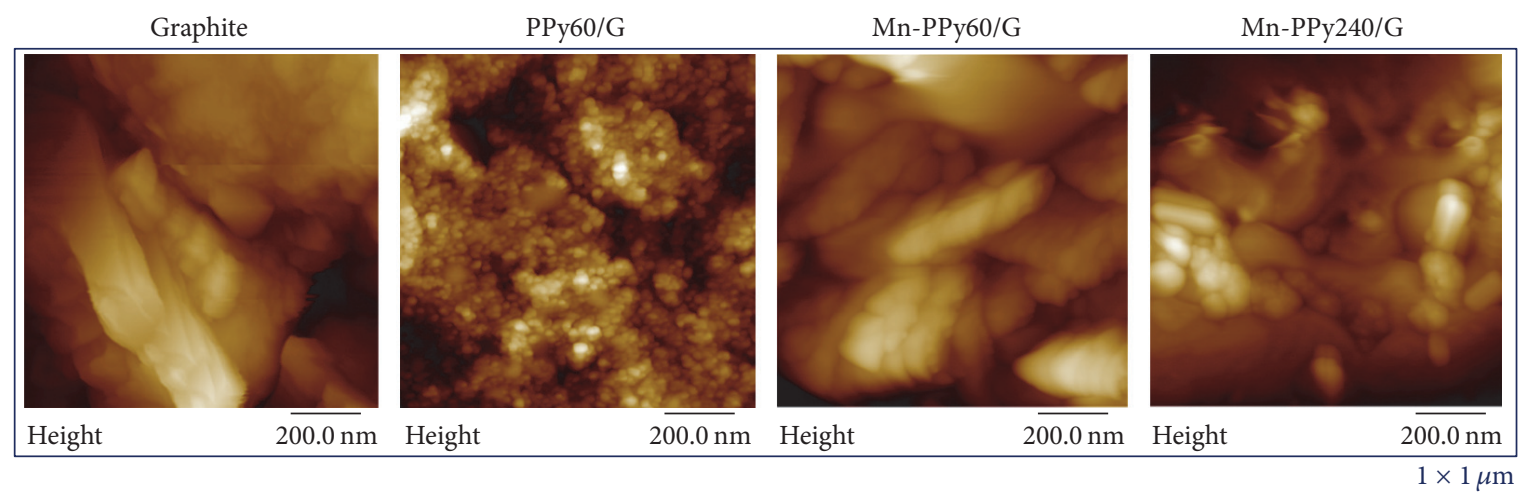

(a)
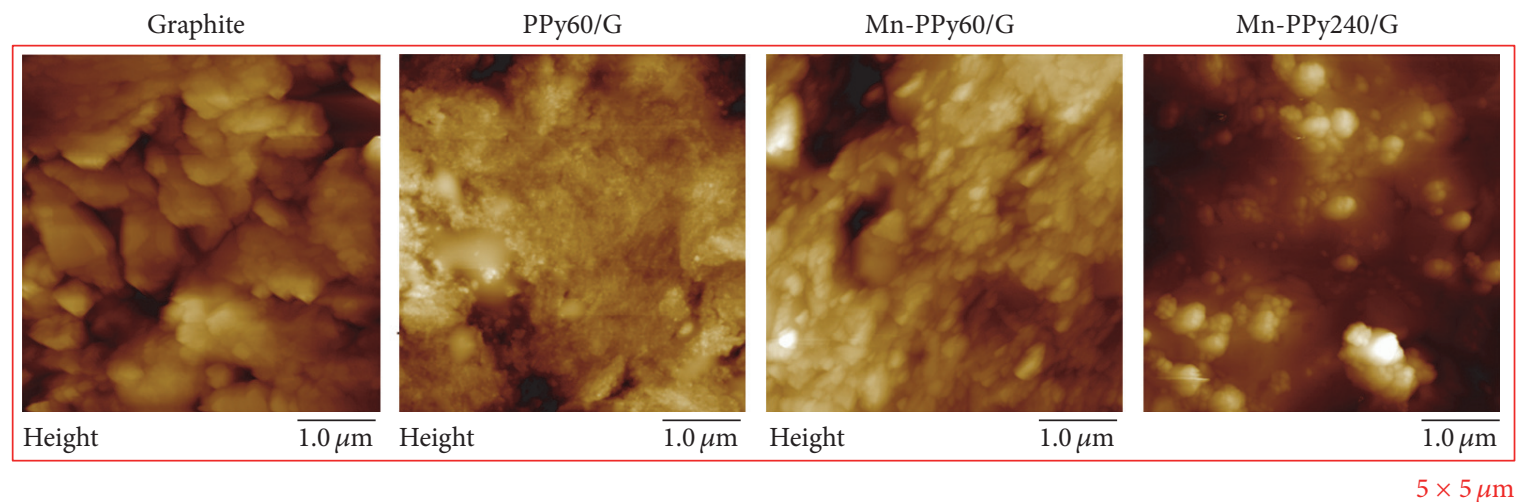

(b)

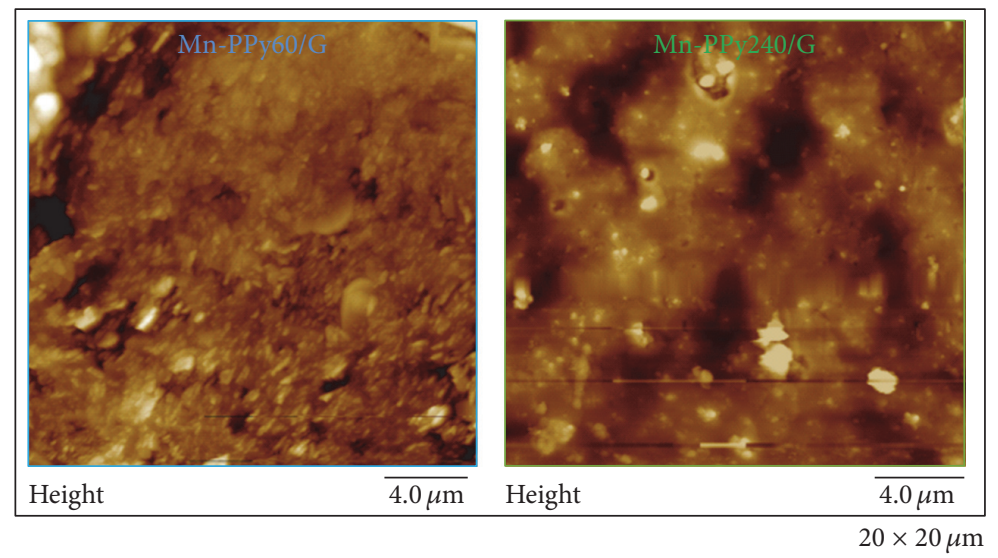

(c)

Figure 5: AFM height images of the graphite $(\mathrm{G})$ substrate as well as of the following: PPy60/G, Mn-PPy60/G, and Mn-PPy240/G electrodeposits.

TABLE 2: AFM surface morphology indicators of graphite, PPy, and Mn/PPy samples.

\begin{tabular}{lccccc}
\hline Sample & Ideally flat & Graphite $(\mathrm{G})$ & PPy on graphite (PPy/G) & $\begin{array}{c}\text { Mn/PPy on } \\
\text { graphite } \\
\text { (Mn-PPy60/G) }\end{array}$ & $\begin{array}{c}\text { Mn/PPy on } \\
\text { graphite } \\
(\mathrm{Mn}-\mathrm{PPy} 240 / \mathrm{G})\end{array}$ \\
\hline Particle size/nm & $/$ & $/$ & $21.11 \pm 5.17$ & $215.96 \pm 125.27$ & $120.05 \pm 81$ \\
$R_{A}{ }^{*} / \mathrm{nm}$ & 0 & $60.6 \pm 5.94$ & $25.3 \pm 0.14$ & $100.13 \pm 64$ & $76.03 \pm 61.26$ \\
$R_{\mathrm{Q}}{ }^{* *} / \mathrm{nm}$ & 0 & $80.7 \pm 15.13$ & $35.3 \pm 1.56$ & $133.6 \pm 82.27$ & $98.50 \pm 78.95$ \\
Surface area $/ \mu \mathrm{m}^{2}$ & 100 & $148.6 \pm 11.4$ & $112.7 \pm 0.03$ & $129.68 \pm 7.56$ & $112.04 \pm 9.63$ \\
\hline
\end{tabular}

${ }^{*} R_{A}=$ average roughness.

${ }^{* *} R_{\mathrm{Q}}=$ root mean square roughness. 


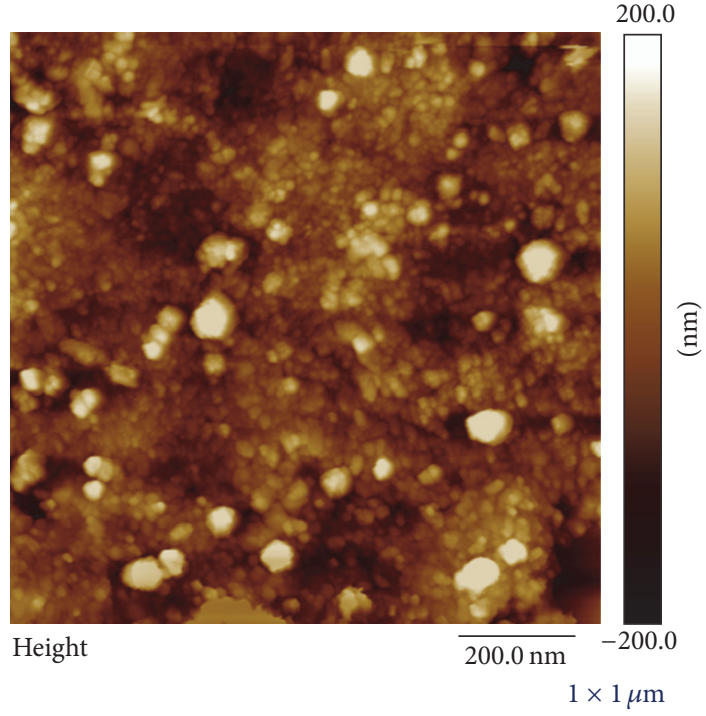

(a)

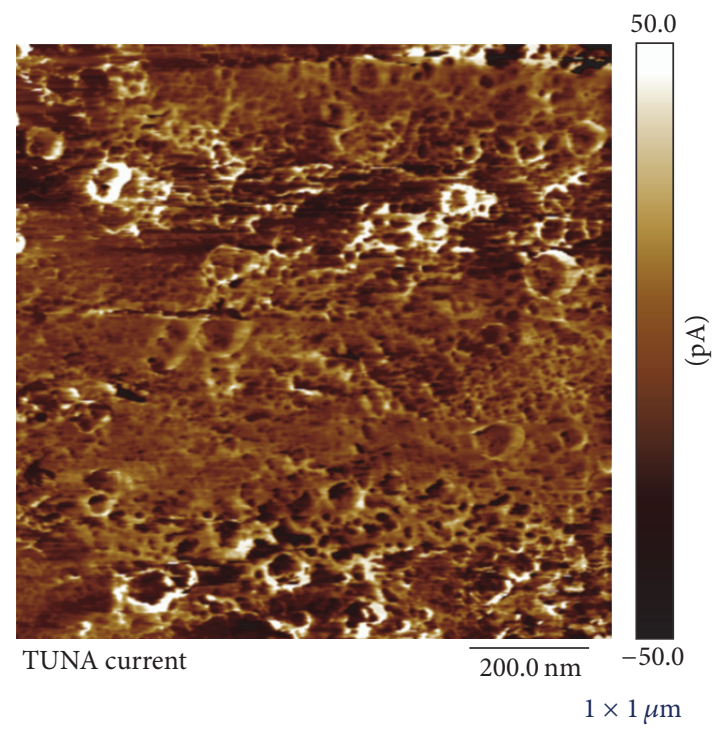

(b)

FIGURE 6: Simultaneous mapping of (a) topography and (b) current of Mn-PPy240/G electrodeposit obtained with PeakForce TUNA.

cycles to cover the graphite surface with a closely packed population of globules having a mean diameter of $21 \pm 5 \mathrm{~nm}$ : a concomitant reduction of the surface area by ca. $25 \%$ is recorded after the electropolymerization process (Table 2). The PPy globular structure shown in Figure 5(a) is typical for PPy thicknesses below $1 \mu \mathrm{m}$ [60], such as in our sample, the mean thickness of which $(\delta)$ has been estimated to be $0.9 \mu \mathrm{m}$ (in good agreement with literature [61]) from the electrical charge $(Q)$ associated with pyrrole oxidation by application of Faraday's law and assuming $100 \%$ current efficiency for polypyrrole formation according to $\delta=Q M / P A z F$, where $M$ is the molar mass of the repetitive unit $\left(67.09 \mathrm{~g} \mathrm{~mol}^{-1}\right), F$ the Faraday constant $\left(96,500 \mathrm{C} \mathrm{mol}^{-1}\right), Q$ the electrical charge, $A$ the working electrode area $\left(1.326 \mathrm{~cm}^{2}\right), P$ the density of the polymer $\left(1.5 \mathrm{~g} \mathrm{~cm}^{-3}\right)$, and $z$ the electron loss $(2.25)[62,63]$. By adding $\mathrm{Mn}^{2+}$ ions to the pyrrole-containing electrolyte and using the same number of electrodeposition cycles (60), the electrodeposition process is no longer able to produce a polymer film covering homogeneously the whole electrode surface. The AFM height images of the Mn-PPy60/G show that the surface is irregular with some uncovered areas and a roughness value that is intermediate between those of $\mathrm{G}$ and PPy60/G (Table 2). Of course, the morphology and metal distribution of $\mathrm{Mn} / \mathrm{PPy}$ composites are affected by a wide range of parameters in a complex way, such as the electronic conductivity of PPy, doping degree, polymer porosity, metal ion transport within the PPy network structure, and chemical interactions between metal ions and their complexes with the polymer. This is chiefly instanced by the spread in $R_{Q}$ values shown in Table 2, since this parameter is the most sensitive to the presence of peaks and valleys among the selected morphology indicators [64]. The morphology of electrodeposited Mn/PPy films improves by increasing the number of cycles to 240: in fact sample Mn-Py240/G is notably more compact and uniform coherently with SEM analysis (Figures 4(c) and 4(d)). In the AFM height images of Figure 4(c) the comparison between the samples Mn$\mathrm{PPy} 60 / \mathrm{G}$ and Mn-PPy240/G can be better appreciated at low magnification $\left(20 \times 20 \mu \mathrm{m}^{2}\right)$. The thicker sample shows the presence of particles with diameters of $120 \pm 81 \mathrm{~nm}$, uniformly distributed over the whole surface. It is worth noting that the surface area of Mn-PPy240/G and that of the film-covered areas of Mn-PPy60/G are similar. The quality of the Mn-PPy240/G deposit is coherent with the superior ORR performance, discussed in Section 3.4.

Figure 6 shows typical topography (a) and current (b) images obtained simultaneously from the surface of the MnPPy240/G film. The current image clearly shows that the nanocomposite exhibits heterogeneous surface conductivity. By comparing Figures 6(a) and 6(b) one can straightforwardly conclude that the top regions of the particles are not conductive while current preferentially flows at the border of the particles. This finding suggests that the grain can be composed of poorly conductive manganese oxides, with PPy in the reduced state, coherently with XRF mapping and micro-XAS analysis [51] as well as Raman Spectroscopy (see next section). Moreover, our results are in keeping with a previous study, showing that the top of PPy globules is preferentially reduced during electrodeposition [60].

(3) Raman Spectroscopy. Micro-Raman Spectroscopy has been employed to characterize the PPy60/G, Mn-PPy60/G, and Mn-PPy240/G samples. In Figure 7(a) the Raman spectra of all PPy-containing samples display the typical prominent PPy bands [48]. Two of the three characteristic bands associated with the reduced/undoped $\left(994,1052 \mathrm{~cm}^{-1}\right)$ and to the oxidized/doped form $\left(938,1090 \mathrm{~cm}^{-1}\right)$ of PPy can also be appreciated. The other bands at $1564 \mathrm{~cm}^{-1}$ (reduced) and $1612 \mathrm{~cm}^{-1}$ (oxidized) are overwhelmed by the graphite signal. As is well documented in literature, the oxidation/reduction 

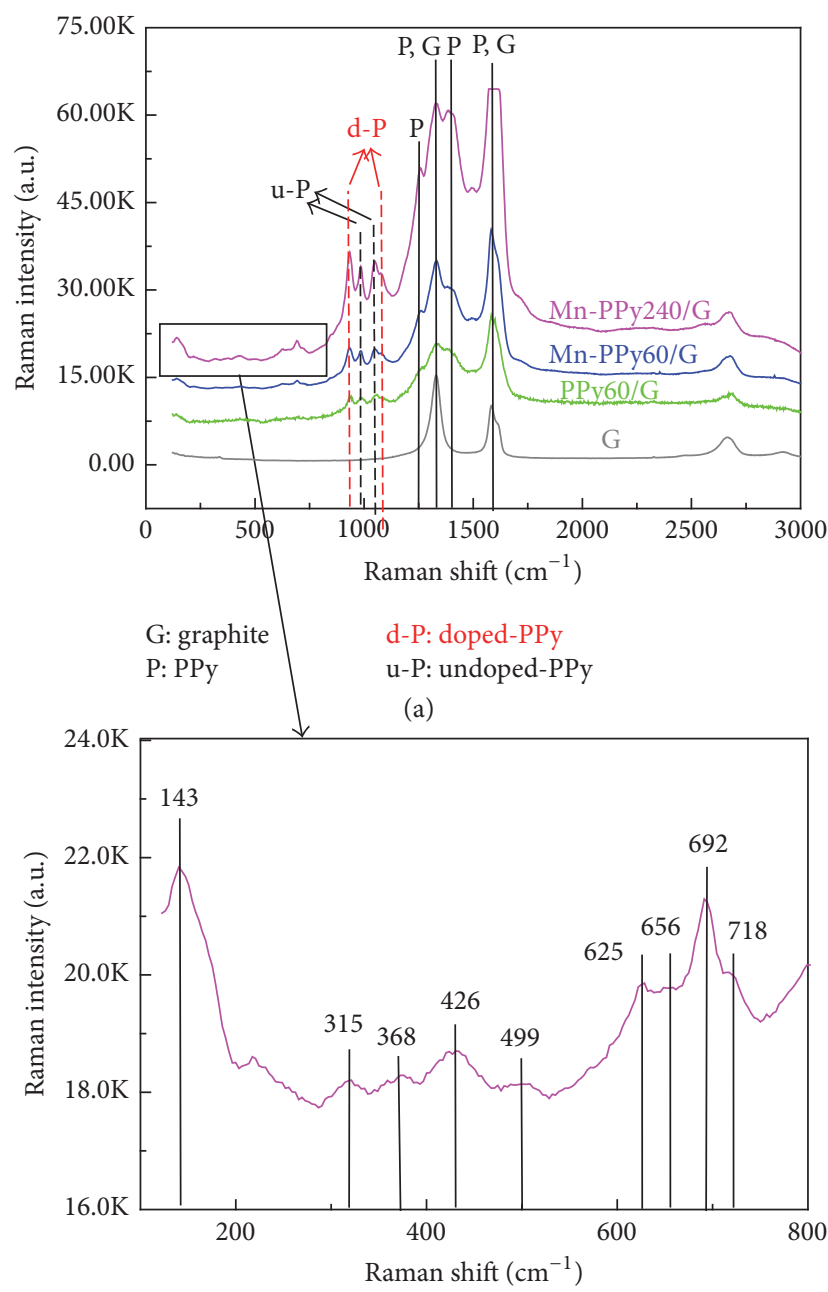

(b)

Figure 7: (a) Micro-Raman spectra of the graphite support (G) and of PPy60/G, Mn-PPy60/G, and Mn-PPy240/G electrodeposited catalysts. (b) Magnification in the range $100-800 \mathrm{~cm}^{-1}$ to highlight the $\mathrm{MnO}_{x}$ features.

processes of PPy involve the fully reduced state $\left(\mathrm{PP}^{0}\right)$, the oxidized state bipolaron $\left(\mathrm{PP}^{2+}\right)$ and the intermediate oxidized state polaron $\left(\mathrm{PPy}^{+\bullet}\right)$ according to $\mathrm{PPy}^{0} \leftrightarrow \mathrm{PPy}^{+\bullet} \leftrightarrow \mathrm{PPy}^{2+}$. The bands located at about 994 and $938 \mathrm{~cm}^{-1}$ belong to ring deformations associated with bipolaron (dication) and polaron (radical cation), respectively $[65,66]$, while the two peaks revealed at about 1090 and $1052 \mathrm{~cm}^{-1}$ can be attributed to the $\mathrm{N}-\mathrm{H}$ in-plane deformation of oxidized and reduced polypyrrole state [67]. In the composite $\mathrm{Mn} / \mathrm{PPy}$ samples some peaks appear in the range $100-800 \mathrm{~cm}^{-1}$ and become more intense in the thicker sample, where the Raman signal increases presumably due to the SERS effect discussed in [49]. According to the literature, the bands in the range 200$500 \mathrm{~cm}^{-1}$ (see also Figure 7(b)) can be attributed to the Mn$\mathrm{O}-\mathrm{Mn}$ bending mode in the $\mathrm{MnO}_{2}$ lattice and those in the range $500-700 \mathrm{~cm}^{-1}$ to the $\mathrm{Mn}-\mathrm{O}$ stretching of octahedral $\mathrm{MnO}_{6}$ groups [68-71]. The main band at $692 \mathrm{~cm}^{-1}$ is typically attributed to $\mathrm{Mn}_{2} \mathrm{O}_{3}$ [71], while the $625 \mathrm{~cm}^{-1}$ feature is reported as the main band of $\beta-\mathrm{MnO}_{2}$ [71] and the one at $143 \mathrm{~cm}^{-1}$ is reported to be the $\mathrm{B} 1 \mathrm{~g}$ mode of rutile-type $\beta$ $\mathrm{MnO}_{2}$ [71]. The concomitant presence of the four features at $315,368,499$, and $656 \mathrm{~cm}^{-1}$ is usually ascribed to $\mathrm{Mn}_{3} \mathrm{O}_{4}$ $[71,72]$, but some of these bands can also appear in $\mathrm{MnO}_{2}$ $[71,73], \mathrm{Mn}_{2} \mathrm{O}_{3}$ [72], or $\mathrm{MnO}[72,74]$. Even though the positions of Raman bands alone are not enough to support a conclusive speciation of Mn oxides not only owing to the intrinsic complexity of these vibrational spectra [68] but also owing to inconsistent literature in the field $[75,76]$, our Raman results, in combination with previous micro-XAS data [51], definitively prove that the electrodeposition process yields a mixture of $\mathrm{Mn}(\mathrm{II}, \mathrm{III}, \mathrm{IV})$ oxides.

3.4. The RDE Experiment at $G, G / P P y$, and $M n-P P y / G$ Electrodes in $0.1 \mathrm{M} \mathrm{KOH}$. The ORR electrocatalytic activity of the G substrate and that of electrodeposited PPy/G and Mn$\mathrm{PPy} / \mathrm{G}$ films have been evaluated through RDE measurements at different rotation speeds in $0.1 \mathrm{M} \mathrm{KOH}$ solution (Figures 8 and 9). The RDE steady-state voltammograms shown in Figures 8(a)-8(c) and 9(a) have been replicated three times at every rotation speed to check the electrode stability. In order to evaluate the catalytic efficiency comprehensively, electrocatalytic figures of merit have been estimated from RDE polarization curves obtained at $1600 \mathrm{rpm}$. The G substrate shows the two typical ORR waves reported for graphite in alkaline conditions [77]. In particular, the $\mathrm{RDE}$ polarization curve reported in [78] for bare graphite in an $\mathrm{O}_{2}$-saturated $0.1 \mathrm{M} \mathrm{KOH}$ solution at $1600 \mathrm{rpm}$ fits very well with our curve reported in Figure 8(a). The KouteckyLevich plots (Figure $8(\mathrm{~d})$ ) at different electrode potentials display good linearity and the slopes are constant over the potential range from 0 to $0.9 \mathrm{~V} / \mathrm{RHE}$, providing an electron transfer number around 2.3, independent of potential. This finding suggests that ORR on graphite in alkaline solution proceeds principally by the two-electron transfer to give peroxide ions and that no further reduction of $\mathrm{HO}_{2}{ }^{-}$occurs, as generally accepted in literature $[77,79]$. The current density in the LSV curves shown in Figure 8(a) has been calculated considering the geometric area of the graphite electrode; we have not considered the effective surface area estimated by AFM (Table 2) because for ORR electrocatalysts the impact of pore diameter can be more important than that of surface area [80] since micropores can be inactive [81].

The RDE curves recorded with PPy60/G and MnPPy60/G electrodes show a double wave structure that is less pronounced than the one observed with the bare graphite electrode (Figures 8(b), 8(c), and 9(a)). With the increasing of the rotation speed, the diffusion limited current plateau becomes inclined and this slope increases. This behaviour is quite common in the literature for carbon-based catalysts (pyrolyzed $\mathrm{Mn}, \mathrm{Co}, \mathrm{Fe} / \mathrm{PPy}$ [47], $\mathrm{Ag}-\mathrm{MnO}_{2}$ [82], pyrolyzed $\mathrm{Fe}(\mathrm{III})$-tetramethoxyphenyl porphyrin [21], pyrolyzed cobalt [83] and iron phthalocyanine [84], and N-doped carbon nanotubes [85]) and has been attributed to the a heterogeneous distribution of the active sites on the surface catalyst [86, 87]. The ORR performance of our PPy60/G film is superior to that of PPy prepared by a polymerization process via chemical oxidation with $\mathrm{FeCl}_{3}[88]$ : both the onset $\left(E_{\text {onset }}\right)$ 


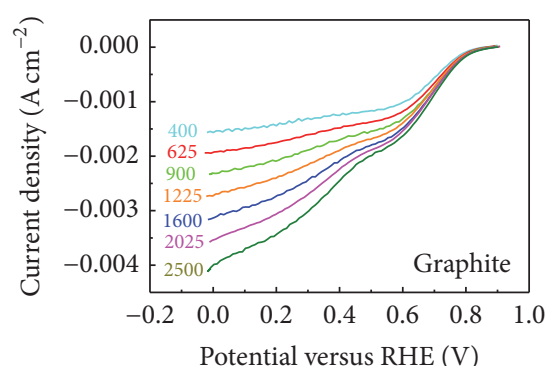

(a)

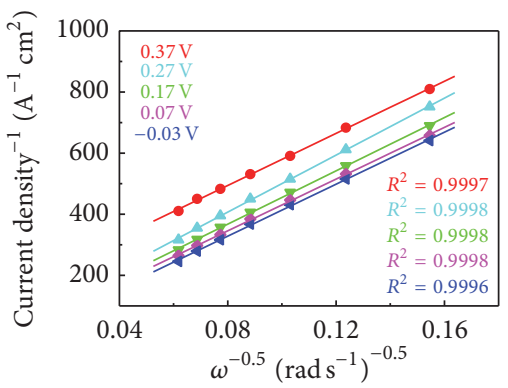

(d)

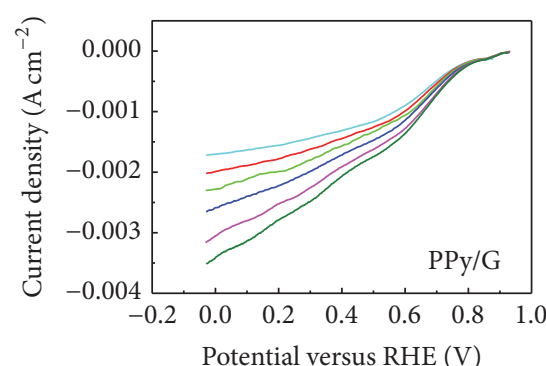

(b)

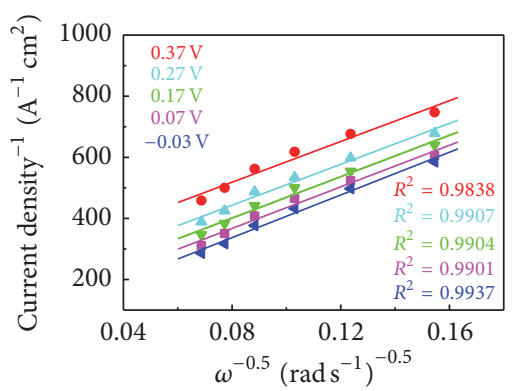

(e)

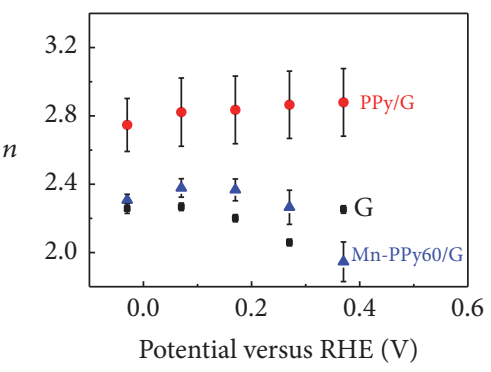

(g)

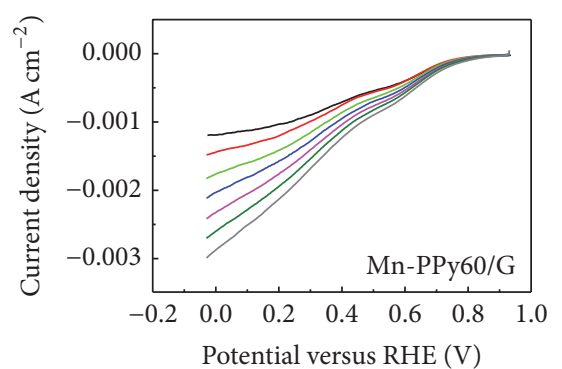

(c)

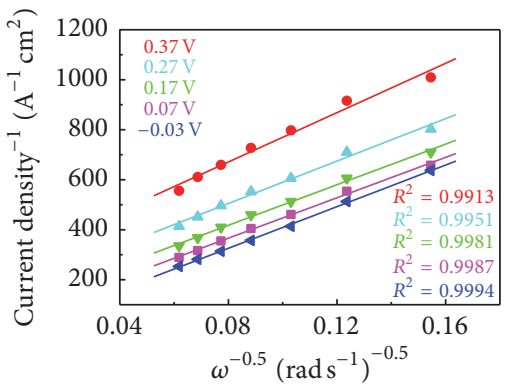

(f)

FIGURE 8: RDE voltammograms (scan rate: $5 \mathrm{mV} \mathrm{s}^{-1}$ ) in $\mathrm{O}_{2}$-saturated $0.1 \mathrm{M} \mathrm{KOH}$ at different rotation speeds of (a) G, (b) PPy/G, and (c) Mn-PPy60/G electrodeposits. The $\mathrm{N}_{2}$ background has been subtracted. (d-f) Koutecky-Levich plots derived from the curves of Panels (a, $\mathrm{b}, \mathrm{c})$ at a series of representative potentials. Symbols are experimental data; lines are the linear regressions. (g) Dependence of the electron transfer number $n$ on the electrode potential.

and half-wave $\left(E_{1 / 2}\right)$ potentials shift to more positive values, from 0.72 to $0.85 \mathrm{~V} / \mathrm{RHE}$ and from 0.34 to $0.69 \mathrm{~V} / \mathrm{RHE}$, respectively. Moreover, the current density at $0.5 \mathrm{~V} / \mathrm{RHE}$ increases from 1.8 to $2.2 \mathrm{~mA} \mathrm{~cm}^{-2}$. The $\mathrm{K}-\mathrm{L}$ results $(n=$ 2.74, Table 2) suggest that the $\mathrm{O}_{2}$ reduction at PPy60/G follows a combination of $2 e^{-}$(reduction of $\mathrm{O}_{2}$ to $\mathrm{HO}_{2}{ }^{-}$) and $4 e^{-}\left(\mathrm{O}_{2}\right.$ is directly reduced to $\left.\mathrm{OH}^{-}\right)$reactions. Coherently with the rather heterogeneous morphology observed by AFM (Section 3.3.1's (2)), the ORR performance of the MnPPy60/G catalyst is not significantly improved with respect to that of the Mn-free PPy60/G sample and the number of exchanged electron returns to a value of 2.25 , similar to that of graphite, while the current density decreases notably (Table 2). The RDE analyses conducted on the Mn-PPy240/G sample, exhibiting the best morphology, are reported in Figure 9. The Koutecky-Levich plots and the correspondent $n$ values at selected potentials (Figures 9(b) and 9(c)) indicate that $4 e^{-}$oxygen reduction process is favoured similarly to poly-Pt electrode in the same ambient. In addition, $E_{\text {onset }}$ and $E_{1 / 2}$ potentials increase with respect to all the other samples reaching values very similar to poly-Pt (Table 3) and carbon/PPy materials [89]. On the contrary, the current density of the Mn-PPy240/G sample in the whole potential range analyzed is lower with respect to the benchmark polyPt. The expected lower catalytic activity of Mn/PPy with respect to poly-Pt is also evidenced in the Tafel plots of Figures 3(d) (poly-Pt) and 8(d) (Mn-PPy240/G). The Tafel slope for the Mn-PPy $240 / \mathrm{G}$ is ca. $122 \mathrm{mV} \mathrm{dec}^{-1}$, notably higher than that found for ploy-Pt: ca. $50 \mathrm{mV} \mathrm{dec}^{-1}$, and suggests an electron transfer mechanism with adsorption molecular oxygen as the rate-determining step [47]. These values are in agreement with the literature, reporting values close to $120 \mathrm{mV} \mathrm{dec}^{-1}$ for $\mathrm{Mn}$ oxides $\left(114 \mathrm{mV} \mathrm{dec}^{-1}\right.$ for $\gamma$ $\mathrm{MnO}_{2} / \mathrm{C}$ [90], $120 \mathrm{mV} \mathrm{dec}{ }^{-1}$ for high $\mathrm{Mn}_{x} \mathrm{O}_{y}$ load/C [91]).

\section{Conclusions}

Poly-Pt has been characterized as intralaboratory benchmark material for the assessment of the ORR electrocatalytic activity of $\mathrm{Mn} /$ polypyrrole nanocomposites based 




(a)

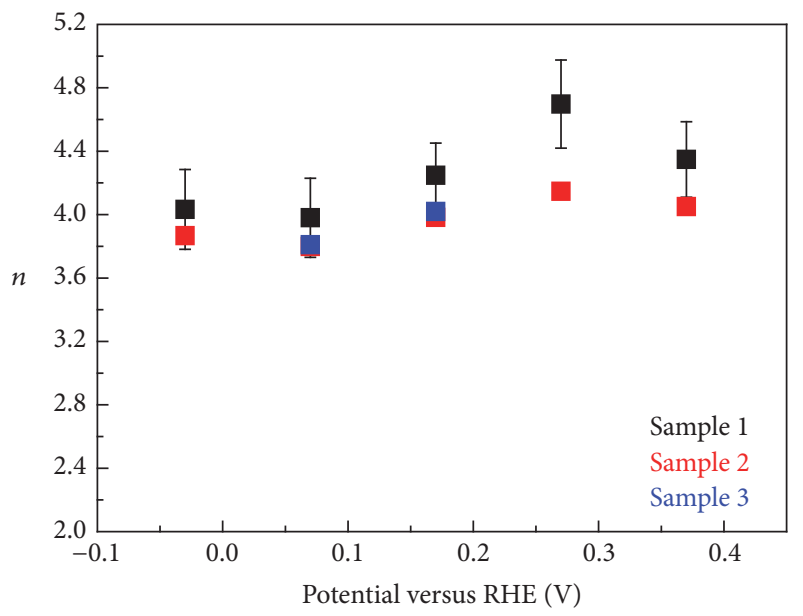

(c)

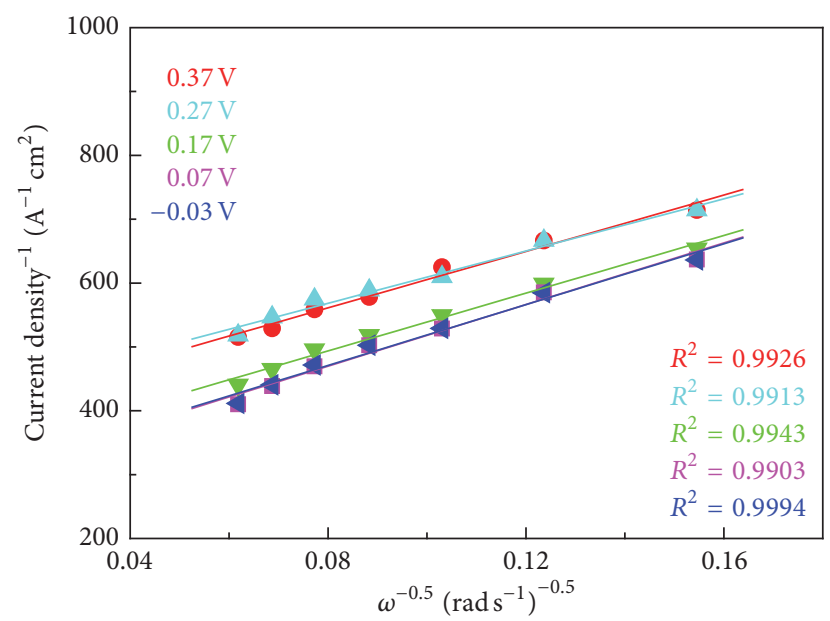

(b)

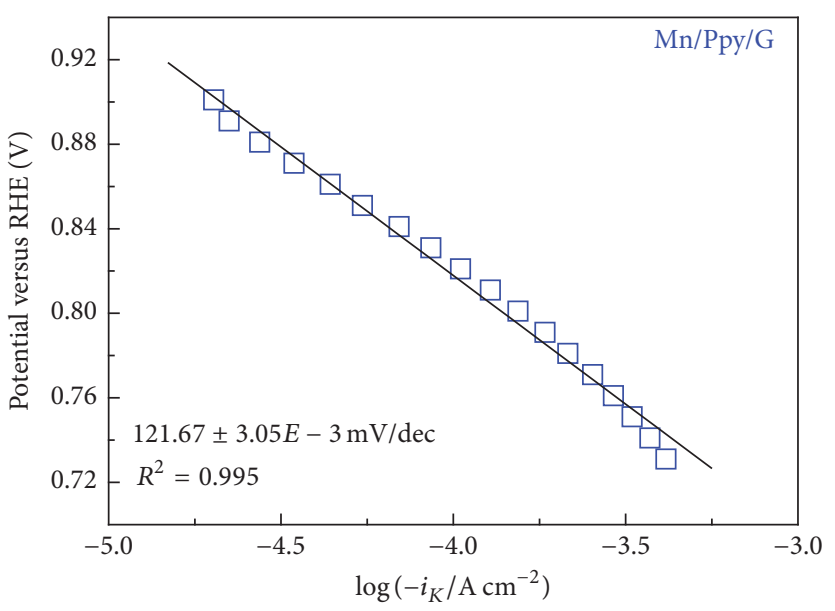

(d)

FIGURE 9: (a) RDE voltammograms (scan rate: $5 \mathrm{mV} \mathrm{s}^{-1}$ ) of Mn-PPy240/G catalyst in $\mathrm{O}_{2}$-saturated $0.1 \mathrm{M} \mathrm{KOH}$ at different rotation speeds. The $\mathrm{N}_{2}$ background has been subtracted. (b) Koutecky-Levich plots derived from the curves of Panel (a) at a series of representative potentials. Symbols are experimental data; lines are the linear regressions. (c) Dependence of the electron transfer number $n$ on the electrode potential for three replicated samples. (d) Tafel plot obtained from RDE voltammograms at $1600 \mathrm{rpm}$.

TABLE 3: ORR electrocatalytic parameters of graphite, PPy, and Mn/PPy catalysts obtained by RDE voltammograms (scan rate: 5 mV s ${ }^{-1}$ ) in $\mathrm{O}_{2}$-saturated $0.1 \mathrm{M} \mathrm{KOH}$ at $1600 \mathrm{rpm}$.

\begin{tabular}{lccrr}
\hline WE & $E_{\text {onset }}, \mathrm{V} / \mathrm{RHE}$ & $E_{1 / 2}, \mathrm{~V} / \mathrm{RHE}$ & $i$ at $E=0.5 \mathrm{~V} / \mathrm{RHE} / \mathrm{mA} \mathrm{cm}^{-2}$ & 4.12 \\
Poly-Pt & 0.871 & 0.72 & 1.78 & $3.79 \pm 0.09$ \\
Graphite & 0.82 & 0.7 & 2.16 & $2.21 \pm 0.08$ \\
PPy on graphite (PPy/G) & 0.85 & 0.69 & 1 & $2.74 \pm 0.19$ \\
Mn-PPy on graphite (Mn-PPy60/G) & 0.846 & 0.65 & 1.65 & $2.25 \pm 0.18$ \\
Mn-PPy on graphite (Mn-PPy240/G) & 0.9 & 0.714 & $4.08 \pm 0.25$ \\
\hline
\end{tabular}

on RDE measurements. Accurate electrocatalytic data of $\mathrm{Mn} / \mathrm{PPy}$ film-complemented with structural and morphological characterizations (FE-SEM, AFM, and Raman)-have been used to disentangle intrinsic electroactivity factors from surface coverage effects and have allowed optimizing the electrodeposition process parameters in view of global electrocatalytic activity. In particular, $\mathrm{Mn} / \mathrm{PPy}$ grown with 240 electrodeposition cycles leads to the formation of continuous film catalytic particles ca. $120 \mathrm{~nm}$ in diameter. AFM PF-TUNA current imaging shows that the top region of these particles - probably consisting of $\mathrm{MnO}_{x}$ and reduced $\mathrm{PPy}$-are poorly conductive and that the current preferentially flows at their border, where-owing to the prevailing current density distribution-polypyrrole is mainly in the oxidized state. These results are coherent with previous XRF mapping and micro-XAS analysis and with Raman 
Spectroscopy results reported in this paper that confirm the presence of the characteristic bands associated with the reduced/undoped and with the oxidized/doped form of PPy and of $\mathrm{Mn}(\mathrm{II}, \mathrm{III}, \mathrm{IV}) \mathrm{O}_{x}$. High-quality Mn/PPy electrodeposits exhibit a superior electrocatalytic activity due to higher four-electron-transfer selectivity for the ORR in alkaline solution, with respect to materials of the same chemistry grown suboptimal electrodeposition parameters. Moreover, optimized Mn/PPy exhibits electrocatalytic figures of merit such as $E_{\text {onset }}$ and $E_{1 / 2}$ potentials that are similar to those of poly-Pt, even though at lower nominal current densities.

\section{Competing Interests}

The authors declare that there is no conflict of interests regarding the publication of this paper.

\section{Acknowledgments}

The authors are grateful to Professor Giovanna Giacalone for her accurate English revision throughout the manuscript.

\section{References}

[1] K. Shinozaki, J. W. Zack, R. M. Richards, B. S. Pivovar, and S. S. Kocha, "Oxygen reduction reaction measurements on platinum electrocatalysts utilizing rotating disk electrode technique. I. Impact of impurities, measurement protocols and applied corrections," Journal of the Electrochemical Society, vol. 162, no. 10, pp. F1144-F1158, 2015.

[2] R. J. Roethlein and H. J. R. Maget, "The electrochemical reduction of oxygen on electrodes partially immersed in phosphoric acid," Journal of The Electrochemical Society, vol. 113, no. 6, pp. 581-585, 1966.

[3] S. D. Fritts, D. Gervasio, R. L. Zeller, and R. F. Savinell, "Investigation of $\mathrm{H}_{2}$ gas transport in recast Nafion films coated on platinum in hydrogen saturated $85 \%$ phosphoric acid," Journal of the Electrochemical Society, vol. 138, no. 11, pp. 33453349, 1991.

[4] A. A. Gewirth and M. S. Thorum, "Electroreduction of dioxygen for fuel-cell applications: materials and challenges," Inorganic Chemistry, vol. 49, no. 8, pp. 3557-3566, 2010.

[5] F. H. B. Lima, J. Zhang, M. H. Shao et al., "Catalytic activityd-Band center correlation for the $\mathrm{O}_{2}$ reduction reaction on platinum in alkaline solutions," Journal of Physical Chemistry C, vol. 111, no. 1, pp. 404-410, 2007.

[6] A. M. Trunov, "On the mechanism of oxygen reduction on single-crystal and polycrystalline $\mathrm{Pt}$ electrodes in alkaline media," Russian Journal of Electrochemistry, vol. 51, no. 4, pp. 332-338, 2015.

[7] R. Devivaraprasad, R. Ramesh, N. Naresh, T. Kar, R. Kumar Singh, and M. Neergat, "Oxygen reduction reaction and peroxide generation on shape-controlled and polycrystalline platinum nanoparticles in acidic and alkaline electrolytes," Langmuir, vol. 30, no. 29, pp. 8995-9006, 2014.

[8] W. Jin, H. Du, S. Zheng, H. Xu, and Y. Zhang, "Comparison of the oxygen reduction reaction between $\mathrm{NaOH}$ and $\mathrm{KOH}$ solutions on a Pt electrode: the electrolyte-dependent effect," The Journal of Physical Chemistry B, vol. 114, no. 19, pp. 65426548, 2010.
[9] K. Tammeveski, T. Tenno, J. Claret, and C. Ferrater, "Electrochemical reduction of oxygen on thin-film Pt electrodes in 0.1 M KOH," Electrochimica Acta, vol. 42, no. 5, pp. 893-897, 1997.

[10] K. Tammeveski, M. Arulepp, T. Tenno, C. Ferrater, and J. Claret, "Oxygen electroreduction on titanium-supported thin Pt films in alkaline solution," Electrochimica Acta, vol. 42, no. 19, pp. 2961-2967, 1997.

[11] G. Couturier, D. W. Kirk, P. J. Hyde, and S. Srinivasan, "Electrocatalysis of the hydrogen oxidation and of the oxygen reduction reactions of $\mathrm{Pt}$ and some alloys in alkaline medium," Electrochimica Acta, vol. 32, no. 7, pp. 995-1005, 1987.

[12] S.-M. Park, S. Ho, S. Aruliah et al., "Electrochemical reduction of oxygen at platinum electrodes in $\mathrm{KOH}$ solutionstemperature and concentration effects," Journal of the Electrochemical Society, vol. 133, no. 8, pp. 1641-1649, 1986.

[13] C. F. Zinola, A. M. C. Luna, W. E. Triaca, and A. J. Arvia, "Kinetics and mechanism of the electrochemical reduction of molecular oxygen on platinum in $\mathrm{KOH}$ : influence of preferred crystallographic orientation," Journal of Applied Electrochemistry, vol. 24, no. 6, pp. 531-541, 1994.

[14] A. S. Ryabova, F. S. Napolskiy, T. Poux et al., "Rationalizing the influence of the $\mathrm{Mn}(\mathrm{IV}) / \mathrm{Mn}$ (III) red-ox transition on the electrocatalytic activity of manganese oxides in the oxygen reduction reaction," Electrochimica Acta, vol. 187, pp. 161-172, 2016.

[15] S. Srinivasan, "Fuel cells for extraterrestrial and terrestrial applications," Journal of the Electrochemical Society, vol. 136, no. 2, pp. 41C-48C, 1989.

[16] C. Chakkaravarthy, A. K. A. Waheed, and H. V. K. Udupa, "Zinc-air alkaline batteries-a review," Journal of Power Sources, vol. 6, no. 3, pp. 203-228, 1981.

[17] L. Geniès, R. Faure, and R. Durand, "Electrochemical reduction of oxygen on platinum nanoparticles in alkaline media," Electrochimica Acta, vol. 44, no. 8-9, pp. 1317-1327, 1998.

[18] X. Ge, A. Sumboja, D. Wuu et al., "Oxygen reduction in alkaline media: from mechanisms to recent advances of catalysts," ACS Catalysis, vol. 5, no. 8, pp. 4643-4667, 2015.

[19] Y.-F. Yang, Y.-H. Zhou, and C.-S. Cha, "Electrochemical reduction of oxygen on small palladium particles supported on carbon in alkaline solution," Electrochimica Acta, vol. 40, no. 16, pp. 2579-2586, 1995.

[20] J. Prakash and H. Joachin, "Electrocatalytic activity of ruthenium for oxygen reduction in alkaline solution," Electrochimica Acta, vol. 45, no. 14, pp. 2289-2296, 2000.

[21] S. L. Gojković, S. Gupta, and R. F. Savinell, "Heat-treated iron(III) tetramethoxyphenyl porphyrin chloride supported on high-area carbon as an electrocatalyst for oxygen reduction: part II. Kinetics of oxygen reduction," Journal of Electroanalytical Chemistry, vol. 462, no. 1, pp. 63-72, 1999.

[22] S. L. Gojković, S. Gupta, and R. F. Savinell, "Heat-treated iron(III) tetramethoxyphenyl porphyrin chloride supported on high-area carbon as an electrocatalyst for oxygen reduction: part III. Detection of hydrogen-peroxide during oxygen reduction," Electrochimica Acta, vol. 45, no. 6, pp. 889-897, 1999.

[23] N. Heller-Ling, M. Prestat, J.-L. Gautier, J.-F. Koenig, G. Poillerat, and P. Chartier, "Oxygen electroreduction mechanism at thin $\mathrm{Ni}_{x} \mathrm{Co}_{3-x} \mathrm{O}_{4}$ spinel films in a double channel electrode flow cell (DCEFC)," Electrochimica Acta, vol. 42, no. 2, pp. 197202, 1997.

[24] Y. Hu, Y. V. Tolmachev, and D. A. Scherson, "Rotating ring-disk studies of oxidized nickel hydrous oxide: oxygen evolution and 
pseudocapacitance," Journal of Electroanalytical Chemistry, vol. 468, no. 1, pp. 64-69, 1999.

[25] V. Rashkova, S. Kitova, I. Konstantinov, and T. Vitanov, "Vacuum evaporated thin films of mixed cobalt and nickel oxides as electrocatalyst for oxygen evolution and reduction," Electrochimica Acta, vol. 47, no. 10, pp. 1555-1560, 2002.

[26] J. Ponce, J.-L. Rehspringer, G. Poillerat, and J. L. Gautier, "Electrochemical study of nickel-aluminium-manganese spinel $\mathrm{Ni}_{x} \mathrm{Al}_{1-x} \mathrm{Mn}_{2} \mathrm{O}_{4}$. Electrocatalytical properties for the oxygen evolution reaction and oxygen reduction reaction in alkaline media," Electrochimica Acta, vol. 46, no. 22, pp. 3373-3380, 2001.

[27] T. Poux, F. S. Napolskiy, T. Dintzer et al., "Dual role of carbon in the catalytic layers of perovskite/carbon composites for the electrocatalytic oxygen reduction reaction," Catalysis Today, vol. 189, no. 1, pp. 83-92, 2012.

[28] T. Poux, A. Bonnefont, G. Kéranguéven, G. A. Tsirlina, and E. R. Savinova, "Electrocatalytic oxygen reduction reaction on perovskite oxides: series versus direct pathway," ChemPhysChem, vol. 15, no. 10, pp. 2108-2120, 2014.

[29] X. Cui, Z. Hua, L. Chen, X. Zhang, H. Chen, and J. Shi, "Manganese oxide nanorod-decorated mesoporous ZSM-5 composite as a precious-metal-free electrode catalyst for oxygen reduction," ChemSusChem, vol. 9, no. 9, pp. 1010-1019, 2016.

[30] L. Mao, D. Zhang, T. Sotomura, K. Nakatsu, N. Koshiba, and T. Ohsaka, "Mechanistic study of the reduction of oxygen in air electrode with manganese oxides as electrocatalysts," Electrochimica Acta, vol. 48, no. 8, pp. 1015-1021, 2003.

[31] B. Klápště, J. Vondrák, and J. Velická, “MnOx/C composites as electrode materials II. Reduction of oxygen on bifunctional catalysts based on manganese oxides," Electrochimica Acta, vol. 47, no. 15, pp. 2365-2369, 2002.

[32] A. Flegler, S. Hartmann, H. Weinrich et al., "Manganese oxide coated carbon materials as hybrid catalysts for the application in primary aqueous metal-air batteries," Journal of Carbon Research C, vol. 2, no. 1, pp. 4-17, 2016.

[33] Y. Gorlin and T. F. Jaramillo, "A bifunctional nonprecious metal catalyst for oxygen reduction and water oxidation," Journal of the American Chemical Society, vol. 132, no. 39, pp. 13612-13614, 2010.

[34] K. L. Pickrahn, S. W. Park, Y. Gorlin, H.-B. Lee, T. F. Jaramillo, and S. F. Bent, "Active $\mathrm{MnO}_{x}$ electrocatalysts prepared by atomic layer deposition for oxygen evolution and oxygen reduction reactions," Advanced Energy Materials, vol. 2, no. 10, pp. 1269-1277, 2012.

[35] T. Ohsaka, L. Mao, K. Arihara, and T. Sotomura, "Bifunctional catalytic activity of manganese oxide toward $\mathrm{O}_{2}$ reduction: novel insight into the mechanism of alkaline air electrode," Electrochemistry Communications, vol. 6, no. 3, pp. 273-277, 2004.

[36] F. Jiao and H. Frei, "Nanostructured manganese oxide clusters supported on mesoporous silica as efficient oxygen-evolving catalysts," Chemical Communications, vol. 46, no. 17, pp. 29202922, 2010.

[37] P.-C. Li, C.-C. Hu, H. Noda, and H. Habazaki, "Synthesis and characterization of carbon black/manganese oxide air cathodes for zinc-air batteries: effects of the crystalline structure of manganese oxides," Journal of Power Sources, vol. 298, pp. 102113, 2015.

[38] F. Cheng and J. Chen, "Metal-air batteries: from oxygen reduction electrochemistry to cathode catalysts," Chemical Society Reviews, vol. 41, no. 6, pp. 2172-2192, 2012.
[39] Electric Fuel Air Electrodes, http://electric-fuel.com/rd/zincair/air-electrode/.

[40] H. Nguyen Cong, K. El Abbassi, J. L. Gautier, and P. Chartier, "Oxygen reduction on oxide/polypyrrole composite electrodes: effect of doping anions," Electrochimica Acta, vol. 50, no. 6, pp. 1369-1376, 2005.

[41] A. Deronzier and J.-C. Moutet, "Polypyrrole films containing metal complexes: syntheses and applications," Coordination Chemistry Reviews, vol. 147, pp. 339-371, 1996.

[42] E. Simon, E. Sablé, H. Handel, and M. L'Her, "Electrodes modified by conducting polymers bearing redox sites: $\mathrm{Ni}$ - and Co-cyclam complexes on polypyrrole," Electrochimica Acta, vol. 45, no. 6, pp. 855-863, 1999.

[43] K. H. An, K. K. Jeon, J. K. Heo, S. C. Lim, D. J. Bae, and Y. H. Lee, "High-capacitance supercapacitor using a nanocomposite electrode of single-walled carbon nanotube and polypyrrole," Journal of the Electrochemical Society, vol. 149, no. 8, pp. A1058A1068, 2002.

[44] S. Sadki, P. Schottland, N. Brodie, and G. Sabouraud, "The mechanisms of pyrrole electropolymerization," Chemical Society Reviews, vol. 29, no. 5, pp. 283-293, 2000.

[45] T. Rapecki, M. Donten, and Z. Stojek, "Electrodeposition of polypyrrole-Au nanoparticles composite from one solution containing gold salt and monomer," Electrochemistry Communications, vol. 12, no. 5, pp. 624-627, 2010.

[46] P. Bocchetta, B. Alemán, M. Amati et al., "ORR stability of Mn-Co/polypyrrole nanocomposite electrocatalysts studied by quasi in-situ identical-location photoelectron microspectroscopy," Electrochemistry Communications, vol. 69, pp. 50-54, 2016.

[47] J. Masa, T. Schilling, M. Bron, and W. Schuhmann, "Electrochemical synthesis of metal-polypyrrole composites and their activation for electrocatalytic reduction of oxygen by thermal treatment," Electrochimica Acta, vol. 60, pp. 410-418, 2012.

[48] P. Bocchetta, A. Gianoncelli, M. K. Abyaneh et al., "Electrosynthesis of Co/PPy nanocomposites for ORR electrocatalysis: a study based on quasi-in situ X-ray absorption, fluorescence and in situ Raman spectroscopy," Electrochimica Acta, vol. 137, pp. 535-545, 2014.

[49] P. Bocchetta, M. Amati, L. Gregoratti et al., "Morphochemical evolution during ageing of pyrolysed Mn/polypyrrole nanocomposite oxygen reduction electrocatalysts: a study based on quasi-in situ photoelectron spectromicroscopy," Journal of Electroanalytical Chemistry, vol. 758, pp. 191-200, 2015.

[50] B. Bozzini, A. Gianoncelli, P. Bocchetta, S. Dal Zilio, and G. Kourousias, "Fabrication of a sealed electrochemical microcell for in situ soft X-ray microspectroscopy and testing with in situ co-polypyrrole composite electrodeposition for Pt-free oxygen electrocatalysis," Analytical Chemistry, vol. 86, no. 1, pp. 664670, 2014.

[51] B. Bozzini, P. Bocchetta, B. Alemán et al., "Electrodeposition and pyrolysis of $\mathrm{Mn}$ /polypyrrole nanocomposites: a study based on soft X-ray absorption, fluorescence and photoelectron microspectroscopies," Journal of Materials Chemistry A, vol. 3, no. 37, pp. 19155-19167, 2015.

[52] B. Bozzini, P. Bocchetta, A. Gianoncelli, C. Mele, and M. Kiskinova, "Electrodeposition and ageing of Mn-based binary composite oxygen reduction reaction electrocatalysts," ChemElectroChem, vol. 2, no. 10, pp. 1541-1550, 2015.

[53] Y. U. Pleskov and V. Y. Filinovski, The Rotating Disc Electrode, Consultants Bureau, New York, NY, USA, 1976. 
[54] A. J. Bard and L. R. Faulkner, Electrochemical Methods, John Wiley \& Sons, 1980.

[55] R. E. Davis, G. L. Horvath, and C. W. Tobias, "The solubility and diffusion coefficient of oxygen in potassium hydroxide solutions," Electrochimica Acta, vol. 12, no. 3, pp. 287-297, 1967.

[56] Y. Li, W. Zhou, H. Wang et al., "An oxygen reduction electrocatalyst based on carbon nanotube-graphene complexes," Nature Nanotechnology, vol. 7, no. 6, pp. 394-400, 2012.

[57] A. B. Anderson and R. A. Sidik, "Oxygen electroreduction on $\mathrm{Fe}^{I I}$ and $\mathrm{Fe}^{I I I}$ coordinated to $\mathrm{N}_{4}$ chelates. Reversible potentials for the intermediate steps from quantum theory," Journal of Physical Chemistry B, vol. 108, no. 16, pp. 5031-5035, 2004.

[58] C. Médard, M. Lefèvre, J. P. Dodelet, F. Jaouen, and G. Lindbergh, "Oxygen reduction by Fe-based catalysts in PEM fuel cell conditions: activity and selectivity of the catalysts obtained with two Fe precursors and various carbon supports," Electrochimica Acta, vol. 51, no. 16, pp. 3202-3213, 2006.

[59] K. I. Popov, S. S. Djokic, and B. N. Grgur, Fundamental Aspects of Electrometallurgy, chapter 5, Kluwer, New York, NY, USA, 2002.

[60] H. J. Lee and S.-M. Park, "Electrochemistry of conductive polymers. 30. Nanoscale measurements of doping distributions and current-voltage characteristics of electrochemically deposited polypyrrole films," Journal of Physical Chemistry B, vol. 108, no. 5, pp. 1590-1595, 2004.

[61] R. M. Penner, L. S. Van Dyke, and C. R. Martin, "Electrochemical evaluation of charge-transport rates in polypyrrole," Journal of Physical Chemistry, vol. 92, no. 18, pp. 5274-5282, 1988.

[62] A. F. Diaz, J. I. Castillo, J. A. Logan, and W.-Y. Lee, "Electrochemistry of conducting polypyrrole films," Journal of Electroanalytical Chemistry, vol. 129, no. 1-2, pp. 115-132, 1981.

[63] F. A. Harraz, "Electrochemical polymerization of pyrrole into nanostructured p-type porous silicon," Journal of the Electrochemical Society, vol. 153, no. 5, pp. C349-C356, 2006.

[64] R. R. L. De Oliveira, D. A. C. Albuquerque, T. G. S. Cruz, F. M. Yamaji, and F. L. Leite, Atomic Force MicroscopyImaging, Measuring and Manipulating Surfaces at the Atomic Scale, Measurement of the Nanoscale Roughness by Atomic Force Microscopy: Basic Principles and Applications, Edited by V. Bellitto, InTech, 2012.

[65] J. Duchet, R. Legras, and S. Demoustier-Champagne, "Chemical synthesis of polypyrrole: structure-properties relationship," Synthetic Metals, vol. 98, no. 2, pp. 113-122, 1998.

[66] A. B. Gonçalves, A. S. Mangrich, and A. J. G. Zarbin, "Polymerization of pyrrole between the layers of $\alpha$-Tin(IV) Bis(hydrogenphosphate)," Synthetic Metals, vol. 114, no. 2, pp. 119-124, 2000.

[67] C. J. Zhong, Z. Q. Tian, and Z. W. Tian, "In situ ESR and Raman spectroscopic studies of the electrochemical process of conducting polypyrrole films," Journal of Physical Chemistry, vol. 94, no. 5, pp. 2171-2175, 1990.

[68] C. M. Julien, M. Massot, and C. Poinsignon, "Lattice vibrations of manganese oxides: part I. Periodic structures," Spectrochimica Acta Part A: Molecular and Biomolecular Spectroscopy, vol. 60, no. 3, pp. 689-700, 2004.

[69] Q. Feng, H. Kanoh, and K. Ooi, "Manganese oxide porous crystals," Journal of Materials Chemistry, vol. 9, no. 2, pp. 319333, 1999.

[70] T. Gao, M. Glerup, F. Krumeich, R. Nesper, H. Fjellvåg, and P. Norby, "Microstructures and spectroscopic properties of cryptomelane-type manganese dioxide nanofibers," Journal of Physical Chemistry C, vol. 112, no. 34, pp. 13134-13140, 2008.
[71] T. Gao, H. Fjellvág, and P. Norby, "Structural and morphological evolution of $\beta-\mathrm{MnO}_{2}$ nanorods during hydrothermal synthesis," Nanotechnology, vol. 20, no. 5, pp. 055610-055616, 2009.

[72] J. Jiang and A. Kucernak, "Electrochemical supercapacitor material based on manganese oxide: preparation and characterization," Electrochimica Acta, vol. 47, no. 15, pp. 2381-2386, 2002.

[73] M. Sun, B. Lan, L. Yu et al., "Manganese oxides with different crystalline structures: facile hydrothermal synthesis and catalytic activities," Materials Letters, vol. 86, pp. 18-20, 2012.

[74] B. Liu, X. Hu, H. Xu, W. Luo, Y. Sun, and Y. Huang, "Encapsulation of $\mathrm{MnO}$ nanocrystals in electrospun carbon nanofibers as high-performance anode materials for lithium-ion batteries," Scientific Reports, vol. 4, article 4229, 2014.

[75] R. Baddour-Hadjean and J.-P. Pereira-Ramos, "Raman microspectrometry applied to the study of electrode materials for lithium batteries," Chemical Reviews, vol. 110, no. 3, pp. 12781319, 2010.

[76] T. Gao, H. Fjellvåg, and P. Norby, "A comparison study on Raman scattering properties of $\alpha$ - and $\beta-\mathrm{MnO}_{2}$," Analytica Chimica Acta, vol. 648, no. 2, pp. 235-239, 2009.

[77] C. Song and J. Zhang, "Electrocatalytic oxygen reduction reaction," in PEM Fuel Cell Electrocatalysts and Catalyst Layers: Fundamentals and Applications, pp. 89-134, Springer, Berlin, Germany, 2008.

[78] Z.-W. Liu, F. Peng, H.-J. Wang, H. Yu, W.-X. Zheng, and J. Yang, "Phosphorus-doped graphite layers with high electrocatalytic activity for the $\mathrm{O}_{2}$ reduction in an alkaline medium," Angewandte Chemie-International Edition, vol. 50, no. 14, pp. 32573261, 2011.

[79] D. Qu, "Investigation of oxygen reduction on activated carbon electrodes in alkaline solution," Carbon, vol. 45, no. 6, pp. 12961301, 2007.

[80] J. Maruyama, K.-I. Sumino, M. Kawaguchi, and I. Abe, "Influence of activated carbon pore structure on oxygen reduction at catalyst layers supported on rotating disk electrodes," Carbon, vol. 42, no. 15, pp. 3115-3121, 2004.

[81] A. J. Appleby and J. Marie, "Kinetics of oxygen reduction on carbon materials in alkaline solution," Electrochimica Acta, vol. 24, no. 2, pp. 195-202, 1979.

[82] F.-P. Hu, X.-G. Zhang, F. Xiao, and J.-L. Zhang, "Oxygen reduction on $\mathrm{Ag}-\mathrm{MnO}_{2} / \mathrm{SWNT}$ and $\mathrm{Ag}-\mathrm{MnO}_{2} / \mathrm{AB}$ electrodes," Carbon, vol. 43, no. 14, pp. 2931-2936, 2005.

[83] G. Tamizhmani, J. P. Dodelet, D. Guay, G. Lalande, and G. A. Capuano, "Electrocatalytic activity of Nafion-impregnated pyrolyzed cobalt phthalocyanine: a correlative study between rotating disk and solid polymer electrolyte fuel-cell electrodes," Journal of the Electrochemical Society, vol. 141, no. 1, pp. 41-45, 1994.

[84] G. Lalande, G. Faubert, R. Côté et al., "Catalytic activity and stability of heat-treated iron phthalocyanines for the electroreduction of oxygen in polymer electrolyte fuel cells," Journal of Power Sources, vol. 61, no. 1-2, pp. 227-237, 1996.

[85] R. Bresciani, S. Marzorati, A. Lascialfari, B. Sacchi, N. Santo, and M. Longhi, "Effects of catalyst aging on the growth morphology and oxygen reduction activity of nitrogen-doped carbon nanotubes," Electrochemistry Communications, vol. 51, pp. 27-32, 2015.

[86] R. Jiang and F. C. Anson, "The origin of inclined plateau currents in steady-state voltammograms for electrode processes 
involving electrocatalysis," Journal of Electroanalytical Chemistry and Interfacial Electrochemistry, vol. 305, no. 2, pp. 171-184, 1991.

[87] R. A. Bull, F. R. Fan, and A. J. Bard, "Polymer films on electrodes. 13. Incorporation of catalysts into electronically conductive polymers: iron phthalocyanine in polypyrrole," Journal of the Electrochemical Society, vol. 131, no. 3, pp. 687-689, 1984.

[88] S. Jiang, C. Zhu, and S. Dong, "Cobalt and nitrogencofunctionalized graphene as a durable non-precious metal catalyst with enhanced ORR activity," Journal of Materials Chemistry A, vol. 1, no. 11, pp. 3593-3599, 2013.

[89] X. Yuan, L. Li, Z. Ma et al., "Novel nanowire-structured polypyrrole-cobalt composite as efficient catalyst for oxygen reduction reaction," Scientific Reports, vol. 6, article 20005, 2016.

[90] S. Chao, Z. Lu, Z. Bai et al., "Tuning synthesis of highly active nitrogen-doped graphite and determining the optimal structure from first-principles calculations," International Journal of Electrochemical Science, vol. 8, no. 6, pp. 8786-8799, 2013.

[91] M. L. Calegaro, F. H. B. Lima, and E. A. Ticianelli, "Oxygen reduction reaction on nanosized manganese oxide particles dispersed on carbon in alkaline solutions," Journal of Power Sources, vol. 158, no. 1, pp. 735-739, 2006. 



Carbohydrate Chemistry

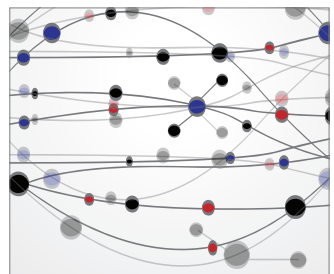

The Scientific World Journal
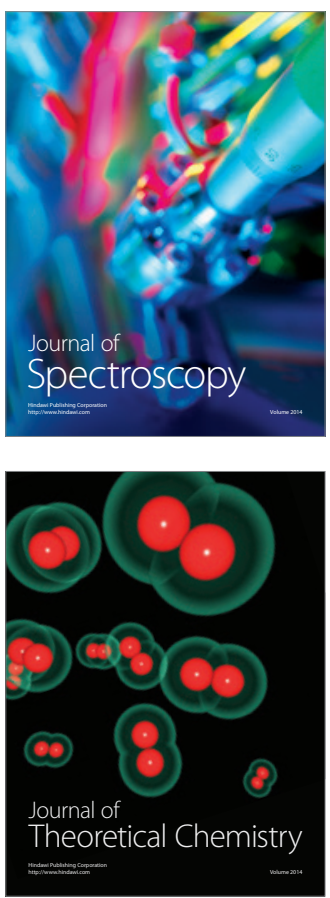
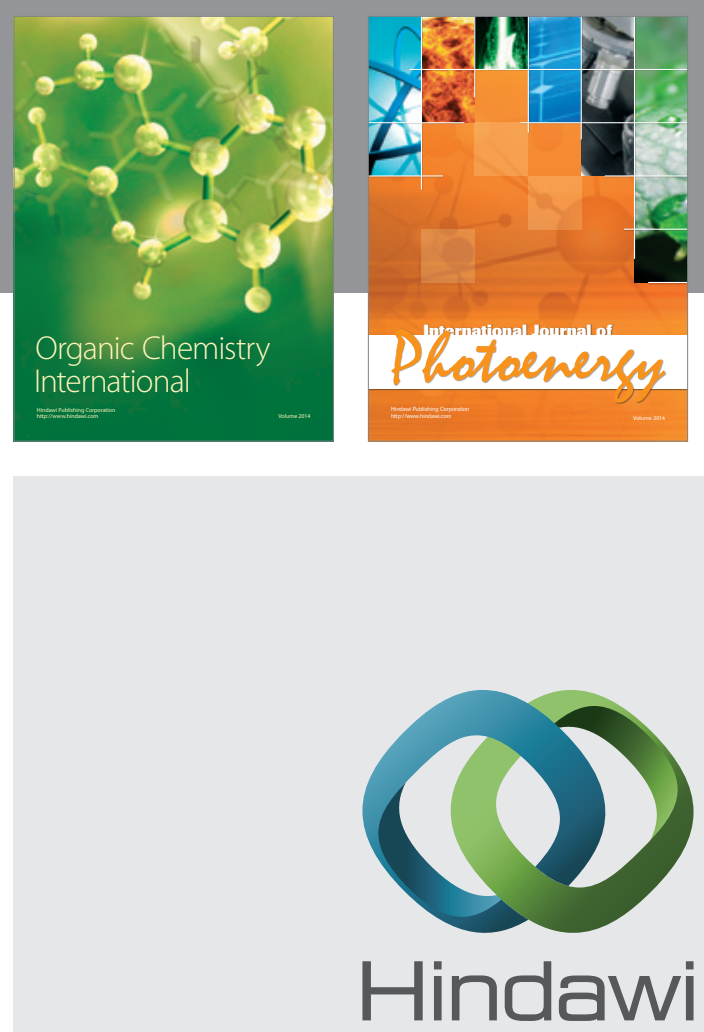

Submit your manuscripts at

http://www.hindawi.com

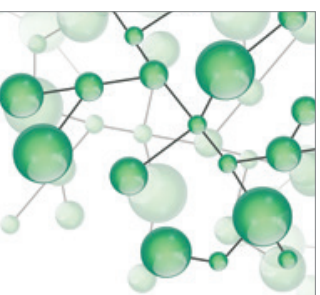

International Journal of

Inorganic Chemistry

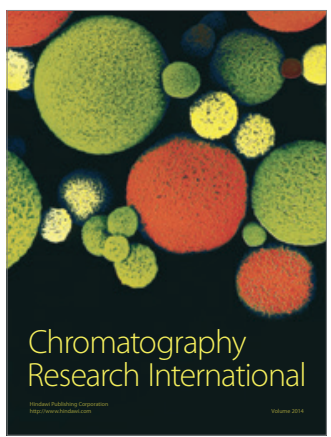

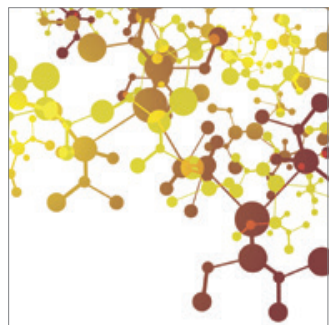

Applied Chemistry
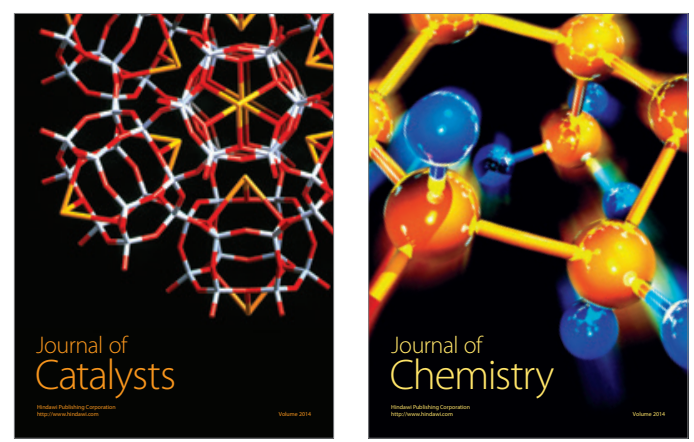
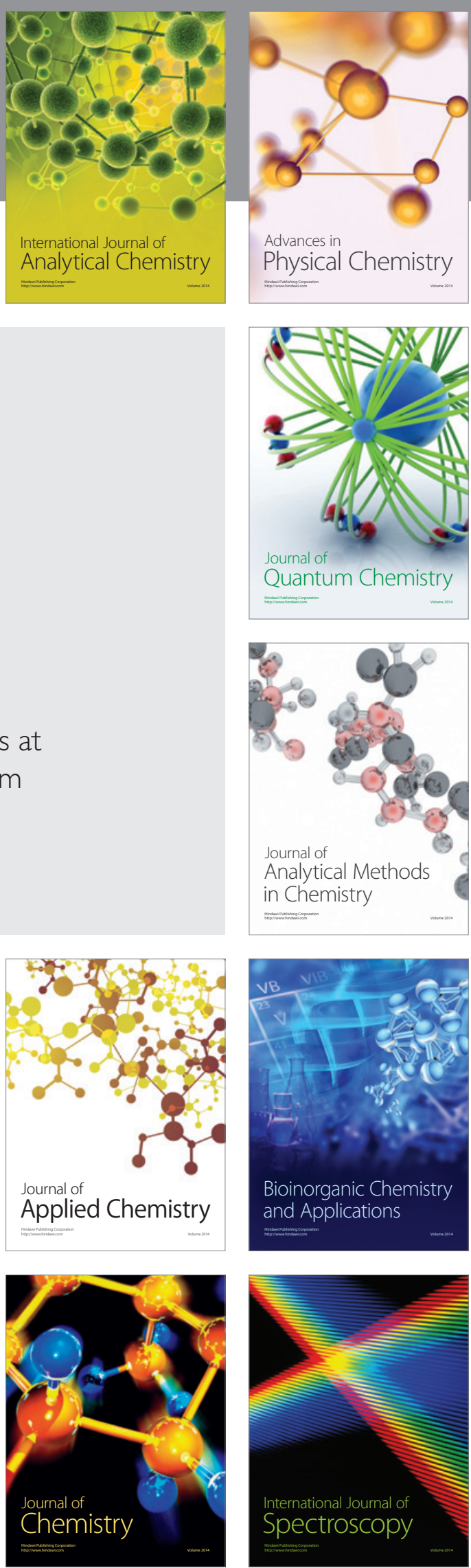